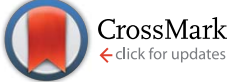

Cite this: J. Mater. Chem. A, 2016, 4, 15266

Received 28th June 2016 Accepted 21st August 2016

DOI: $10.1039 / \mathrm{c} 6 \mathrm{ta0} 5439 \mathrm{k}$

www.rsc.org/MaterialsA

\title{
Interfacial behaviours between lithium ion conductors and electrode materials in various battery systems
}

\begin{abstract}
Bingbin Wu,,$^{a}$ Shanyu Wang, $\varphi^{b}$ Willie J. Evans IV, ${ }^{a}$ Daniel Z. Deng, ${ }^{c}$ Jihui Yang ${ }^{\star b}$ and Jie Xiao*a

In recent years room temperature $\mathrm{Li}^{+}$ion conductors have been intensively revisited in an attempt to develop solid state batteries that can be deployed for vehicle electrification. Through careful modification on materials synthesis, promising solid $\mathrm{Li}^{+}$conductors with competitive ionic conductivity to those of liquid electrolytes have been demonstrated. However, the integration of highly conductive solid electrolytes into the whole system is still very challenging mainly due to the high impedance existing at different interfaces throughout the battery structure. Herein, this work focuses on the overview of the interfacial behaviors between lithium ion (Li-ion) conductors and cathode/anode materials. The origin, evolution and potential solutions to reduce these interfacial impedances are reviewed for various battery systems spanning from $\mathrm{Li}$-ion, lithium sulfur ( $\mathrm{Li}-\mathrm{S})$, lithium oxygen $\left(\mathrm{Li}-\mathrm{O}_{2}\right)$ batteries to lithium metal protection.
\end{abstract}

\section{Introduction}

High ionic conductivity in solids is a very intriguing, yet relatively rare phenomenon ${ }^{1}$ that is extremely interesting for

${ }^{a}$ Department of Chemistry and Biochemistry, University of Arkansas, Fayetteville, AR 72701, USA. E-mail: jiexiao@uark.edu

${ }^{b}$ Department of Materials Science and Engineering, University of Washington, Seattle, WA 98195, USA. E-mail: jihuiy@uw.edu

'Pacific Northwest National Laboratory, Richland, WA 99352, USA

$\uparrow$ These two authors contributed equally to this paper. both fundamental mechanistic studies and practical applications. ${ }^{2}$ For energy storage and conversion technologies, examples can be found in the novel designs of electrochemical cells, sensors, intermedium temperature conversion of natural gas into the liquid form, $e t c .^{3-7}$ Compared with a liquid electrolyte, a high ionic conductivity solid-state electrolyte (SSE) has valuable attributes such as a greatly expanded electrochemical window and superior safety characteristics, both are critical for energy applications. ${ }^{8,9}$ The study of SSEs was intensely pursued in the 1980s with an exemplary case found

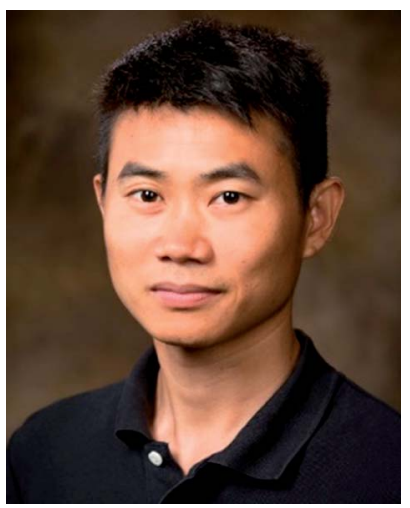

Dr Bingbin $W u$ is currently a post-doctoral research associate in the Department of Chemistry and Biochemistry at University of Arkansas. He received his $P h$. D degree from Wuhan University in 2013. Then he joined Amperex Technology Limited (ATL) as a senior engineer for developing high energy density rechargeable Li metal batteries for about three years. His research interest is to develop high energy density and safe lithium batteries from material design and cell design point of view. Dr Wu has published several journal papers in the field of energy conversion and storage.

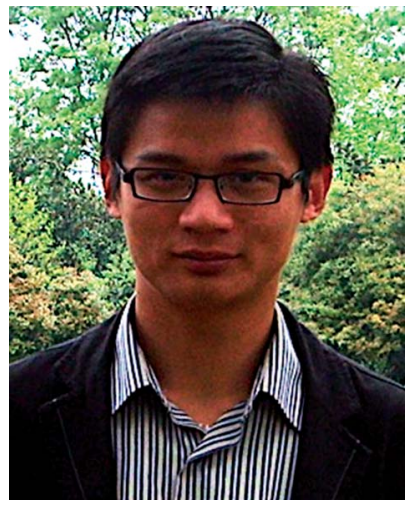

Dr Shanyu Wang is a research associate in the Materials Science and Engineering Department at University of Washington. He received his $P h$. $D$ degree from Wuhan University of Technology in 2012. His research interest mainly focuses on electron, phonon, and ion transport in solids, including thermoelectric semiconductors, superionic conductors, battery materials, etc. Dr Wang has published more than 35 peer-reviewed journal papers in the field of energy conversion and storage. 
in $\beta$-alumina. ${ }^{\mathbf{1 0 - 1 2}}$ After more than a decade of investment in fundamental research, Na- $\beta^{\prime \prime}$-alumina, derived from the $\beta$ alumina, but having higher ionic conductivity, has been successfully commercialized as the electrolyte for sodium batteries operating at $300-350{ }^{\circ} \mathrm{C}$ and is readily adaptable for stationary applications. ${ }^{13}$

In recent years, all-solid-state high-energy Li-ion batteries (LIBs) have been intensively investigated because of their potential for vehicle electrification. Even though the traditional Li-ion batteries and battery management systems (BMS) are well designed and manufactured at an advanced technological level for electrical vehicles (EVs), the thermal runaway of the batteries in EVs remains to be a challenge. This is mainly due to the nature of highly flammable liquid electrolytes under abuse conditions. ${ }^{\mathbf{1 4}}$ Therefore, all-solid-state Li-ion batteries (ASSLIBS) have regained the position of paramount research interest in a hope to overcome the safety issues generic in traditional non-aqueous LIBs. ${ }^{15}$ In addition, the use

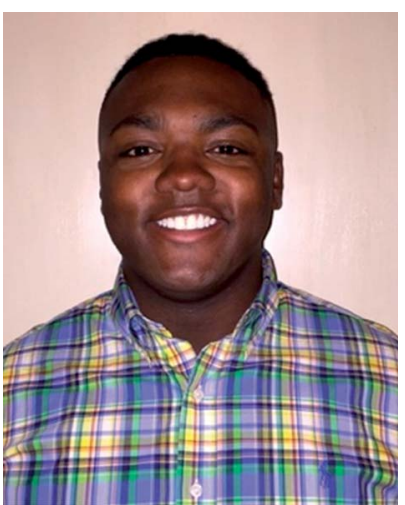

Willie J. Evans IV is currently a Senior in the Chemistry \& Biochemistry Department at the University of Arkansas. He was also a summer technical intern student at Pacific Northwest National Laboratory in 2016. His undergraduate research is focused on utilizing nanotechnology/materials science to produce fuel cells, Proton Exchange Membrane Fuel Cells (PEMFCs) and Phosphoric Acid Fuel Cells (PAFCs). In addition to these areas, his other research is focused on the development of materials for electrode coatings for various lithium battery technologies, such as lithium ion, lithium oxygen, and lithium sulfur.

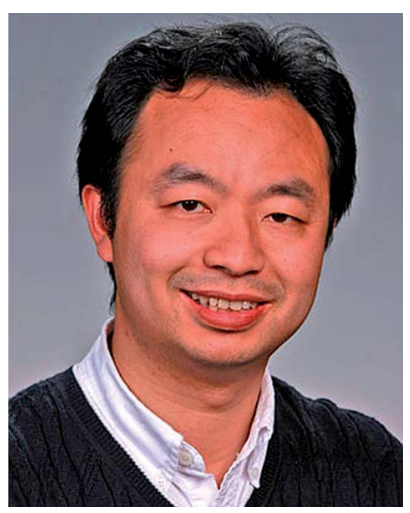

Dr Zhiqun (Daniel) Deng is a Chief Scientist in Energy \& Environment Directorate at Pacific Northwest National Laboratory. He directs the BioAcoustics \& Flow Laboratory (http://bfl.pnnl.gov/), an accredited multi-disciplinary $R \& D$ laboratory, addressing a broad range of engineering and ecological issues, with an emphasis on environmental monitoring and risk assessment for hydropower, wind, marine, and hydrokinetic energy systems. He is currently leading a team consisting of fisheries biologists, chemists, battery scientists, electrical engineers, mechanical engineers, and materials scientists, developing next generation acoustic microtransmitters. of $\mathrm{Li}^{+}$conductive solid electrolytes opens the door for lithium metal in the battery system, which could increase both gravimetric and volumetric energy densities in the solid state cells. The bipolar electrodes can be adopted in a single battery package to further reduce the parasitic weight and dead spaces, which allows the energy density of ASSLIBs to approach and even go beyond those of state-of-the-art LIB technologies. ${ }^{\mathbf{1 6 , 1 7}}$

Li-ion conductors, in general, are poor electronic conductors with the exception of $\mathrm{Li}_{3} \mathrm{~N} .{ }^{7}$ In an ASSLIB, during the charge process, Li-ions come out of the lattice structure of the cathode, pass through the cathode/SSE interfaces, enter the SSE structure (crystalline or amorphous), and SSE-made separator, then move across the SSE/anode interfaces and finally deposit onto the anode if Li metal is used (Fig. 1). The flow direction of Li-ions during the discharge process is simply reversed. For a kinetically efficient $\mathrm{Li}^{+}$diffusion process to occur throughout the system, the limiting steps need to be

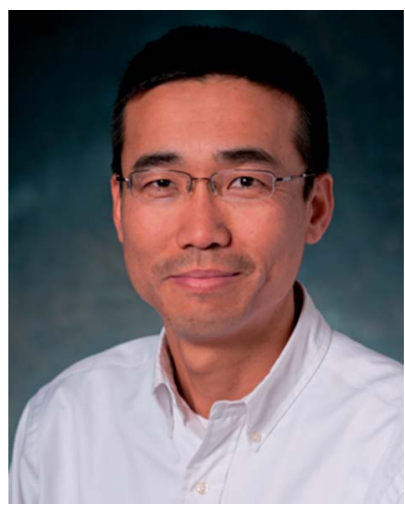

Jihui Yang is currently the Kyocera Associate Professor at the Materials Science and Engineering Department of the University of Washington. Prior to joining the University of Washington in the Fall of 2011, he was a Technical Fellow and Lab Group Manager at GM Research and Development Center, responsible for leading $G M ' s$ research on Li-ion battery materials and systems; as well as advanced thermoelectric materials and technology development. Jihui was elected a Fellow of the American Physical Society in 2012, and has 100 publications, 20 patents, 5 book chapters in the areas of energy materials and applications, to his credit.

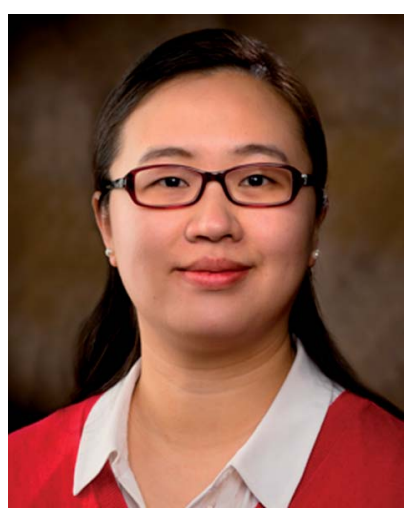

Dr Jie Xiao is an associate professor at the Department of Chemistry \& Biochemistry at University of Arkansas. Before that, she was a senior staff scientist at Pacific Northwest National Laboratory. Dr Xiao has been working in the energy research field for more than ten years and has extensive experience in various battery technologies. She is the recipient of several awards including Ronald L. Brodzinski Early Career Exceptional Achievement Award, R\&D 100 award, etc. Dr Xiao has published more than 80 peer-reviewed journal papers, 2 book chapters and 17 US patents (issued and pending) in the field of energy storage. 


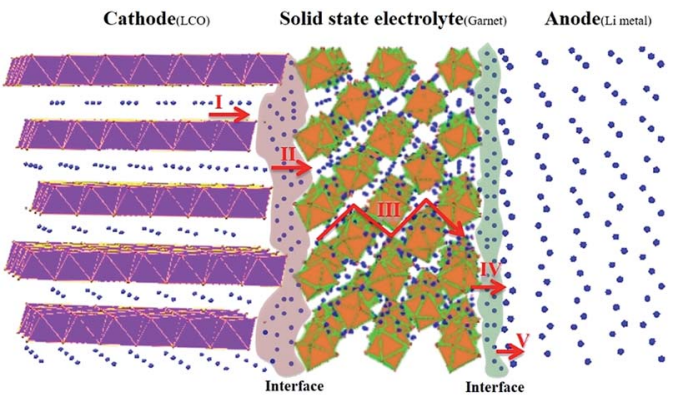

I: $\mathrm{Li}^{+}$cations come out of the lattice structure of cathode;

II: pass through cathode/SSE interface;

III:cross SSE structure (crystalline or amorphous);

IV:move across the SSE/anode interface;

V: finally deposit onto the $\mathrm{Li}$ metal anode.

Fig. 1 The diffusion pathway of Li-ions through an entire ASSLIB during the charging process. The interfacial impedances existing at both the cathode/SSE and the anode/SSE interfaces are the main limiting steps that slow down the transport of Li-ions during the electrochemical processes.

identified to understand the rate-limiting parameters, and thus appropriate methods can be adopted to facilitate the transport of Li-ions, to meet the battery power requirement. Even though the ionic conductivity of SSEs is very important, reflected by the fact that many studies have been dedicated to improving their $\mathrm{Li}^{+}$conductivity, in order to fabricate a practically usable all-solid-sate cell with small voltage polarization, the surface coating (normally SSE) on the electrode materials and the SSE-based separator membrane both need to be very thin. According to Ohm's law, voltage polarization $\Delta E=I R=$ $I((1 / \sigma) L / A)=J L / \sigma$, where $J$ is the current density, and $L, A$, and $\sigma$ are the thickness, cross-section area, and ionic conductivity of the SSE layer, respectively. If a $50 \mathrm{mV}$ voltage drop is allowed at a current density of $3 \mathrm{~mA} \mathrm{~cm} \mathrm{~cm}^{-2}$ (close to $1 \mathrm{C}$ for pouch type cells) and $\sigma$ of the SSE separator is $0.1 \mathrm{mS} \mathrm{cm}^{-1}$, the thickness of the SSE separator needs to be no more than $16.7 \mu \mathrm{m}$. Using such a thin-film SSE separator, the major IR drop would come from the poorly understood interfacial impedance between SSE and the electrodes. ${ }^{18}$

This review first briefly introduces the development history of SSE, then analyzes the attainable specific gravimetric and volumetric energy densities of ASSLIBs, and finally elaborates the fundamental challenges across the electrode materials and SSE interfaces existing in various battery systems including Liion, lithium sulfur ( $\mathrm{Li}-\mathrm{S})$, lithium oxygen $\left(\mathrm{Li}-\mathrm{O}_{2}\right)$ batteries as well as lithium metal protection. For the synthesis and optimization of bulk SSE, quite a few excellent papers ${ }^{19-22}$ have already been published earlier and therefore, will not be repeatedly discussed here.

\section{Brief development history of Li-ion conductors}

The first identification of the Li-ion conductor can be traced back to the $1950 \mathrm{~s}^{23}$ when Masdupuy et al. reported the ionic conductivity of lithium nitride $\left(\mathrm{Li}_{3} \mathrm{~N}\right)$. After that, a few more Li- ion conductors were reported. Fig. 2 illustrates the development history of Li-ion conductors. In 1967, Iyer et al. confirmed the perovskite structure of $\mathrm{Ln}_{1 / 3} \mathrm{NbO}_{3}(\mathrm{Ln}=\mathrm{La}$, Ce, $\mathrm{Pr}, \mathrm{Nd}),{ }^{24}$ followed by the report of ionic conductivity and conduction mechanism of Li-ion in $\operatorname{Li}_{x} \operatorname{Ln}_{1 / 3} \mathrm{Nb}_{1-x} \mathrm{Ti}_{x} \mathrm{O}_{3}(\mathrm{Ln}=$ $\mathrm{La}, \mathrm{Nd}) .{ }^{25}$ Inaguma et al. showed that the bulk ionic conductivity of perovskite-type $\mathrm{Li}_{1 / 2} \mathrm{La}_{1 / 2} \mathrm{TiO}_{3}$ exceeded $10^{-3} \mathrm{~S} \mathrm{~cm}^{-1}$ at room temperature. ${ }^{26}$ In 1969 , the first $\mathrm{Li}^{+}$containing garnet structure $\mathrm{Li}_{3} \mathrm{M}_{2} \mathrm{Ln}_{3} \mathrm{O}_{12}(\mathrm{M}=\mathrm{W}$, Te) was studied by Kasper et $a .^{27} \mathrm{~A}$ garnet-type $\mathrm{Li}_{7} \mathrm{La}_{3} \mathrm{Zr}_{2} \mathrm{O}_{12}$ with a cubic structure was later revisited in 2007 and a high ionic conductivity of $3.7 \times$ $10^{-4} \mathrm{~S} \mathrm{~cm}^{-1}$ at room temperature was demonstrated. ${ }^{28}$ By partial hypervalent substitution of $\mathrm{Zr}$ with $\mathrm{Ta}, \mathrm{Nb}$, Te, etc. , high ionic conductivities exceeding $10^{-3} \mathrm{~S} \mathrm{~cm}^{-1}$ were achieved at room temperature in $2013 .^{29}$ A NASICON-type conductor was discovered by Goodenough et al. in 1976, who described the fast sodium ion conductive behavior in NASICON-type compounds, $\mathrm{Na}_{1+x} \mathrm{Zr}_{2} \mathrm{Si}_{x} \mathrm{P}_{3-x} \mathrm{O}_{12}(0 \leq x \leq 3),{ }^{30}$ inspiring the investigation of Li-ion conductivity in NASICON-like structures. For example, Subramanian et al. reported a NaSICONtype $\mathrm{LiTi}_{2}\left(\mathrm{PO}_{4}\right)_{3}$ with an ionic conductivity of $2 \times 10^{-6} \mathrm{~S} \mathrm{~cm}^{-1}$ at room temperature. ${ }^{31}$ Aono et al. demonstrated that the ionic conductivity of $\operatorname{LiTi}_{2}\left(\mathrm{PO}_{4}\right)_{3}$ can be further improved by partially replacing the $\mathrm{Ti}^{4+}$ with $\mathrm{Al}^{3+}$ and $\mathrm{Sc}^{3+}$. The substituted compounds $\mathrm{Li}_{1.3} \mathrm{Al}_{0.3} \mathrm{Ti}_{1.7}\left(\mathrm{PO}_{4}\right)_{3}$ exhibited a maximum conductivity of $7 \times 10^{-4} \mathrm{~S} \mathrm{~cm}^{-1}$ at $298 \mathrm{~K}$ (ref. 32) and it was further improved to $1.12 \times 10^{-3} \mathrm{~S} \mathrm{~cm}^{-1}$ by using spark plasma sintering to decrease the grain boundary resistance. ${ }^{33,34}$ In 1992, scientists in Oak Ridge National Laboratory developed a novel amorphous solid electrolyte, lithium phosphorus oxynitride (LiPON), by a sputtering method for thin film batteries. The typical composition of LiPON is $\mathrm{Li}_{3.3} \mathrm{PO}_{3.9} \mathrm{~N}_{0.17}$ with a low ionic conductivity of $2 \times 10^{-6} \mathrm{~S} \mathrm{~cm}^{-1}$ at $25{ }^{\circ} \mathrm{C}^{35}$ Because of the low ionic conductivity of LiPON at room temperature, it is mainly used in thin-film batteries. In 1981, Mercier et al. reported superionic conduction in a sulfide glass, $\mathrm{Li}_{2} \mathrm{~S}-\mathrm{P}_{2} \mathrm{~S}_{5}-\mathrm{LiI}$. With a $45 \mathrm{~mol} \% \mathrm{LiI}$ in the sulfide glass, the ionic conductivity reached $10^{-3} \mathrm{~S} \mathrm{~cm}^{-1} \cdot{ }^{36}$ In 2000 , a new crystalline material family, lithium superionic conductor (thio-LISICON), was found in the $\mathrm{Li}_{2} \mathrm{~S}-\mathrm{GeS}_{2}-\mathrm{P}_{2} \mathrm{~S}_{5}$ system by Kanno et $a l .{ }^{37}$ The solid solution member with $x=0.75$ in $\mathrm{Li}_{4-x} \mathrm{Ge}_{1-x} \mathrm{P}_{x} \mathrm{~S}_{4}$ showed the highest conductivity of $2.2 \times 10^{-3}$ $\mathrm{S} \mathrm{cm}^{-1}$ at $25{ }^{\circ} \mathrm{C}$. More recently, the same group reported a novel superionic conductor, $\mathrm{Li}_{10} \mathrm{GeP}_{2} \mathrm{~S}_{12}$, exhibiting a very high lithium ionic conductivity of $12 \mathrm{mS} \mathrm{cm}^{-1}$ at room temperature $^{38}$ which was further improved to $14.2 \mathrm{mS} \mathrm{cm}^{-1}$ by increasing the lithium concentration in $\mathrm{Li}_{10} \mathrm{GeP}_{2} \mathrm{~S}_{12} \cdot{ }^{39}$ The latest work marked the first time that the ionic conductivity of solid electrolytes exceeds those of liquid electrolytes, suggesting attractive applications for ASSLIBs. Seino et al. reported a heat-treated $70 \mathrm{Li}_{2} \mathrm{~S}-30 \mathrm{P}_{2} \mathrm{~S}_{5}$ glass-ceramic conductor with an extremely high ionic conductivity of $17 \mathrm{mS} \mathrm{cm}^{-1}$ at room temperature, mainly due to the reduced grain boundary resistance and the influence of voids. ${ }^{40}$ In 2016, Kato et al. broke the record and reported the highest lithium ionic conductivity of $25 \mathrm{mS} \mathrm{cm}{ }^{-1}$ found in $\mathrm{Li}_{9.54} \mathrm{Si}_{1.74} \mathrm{P}_{1.44} \mathrm{~S}_{11.7} \mathrm{Cl}_{0.3}$, a very promising SSE for energy storage devices. ${ }^{\mathbf{1 6}}$ 


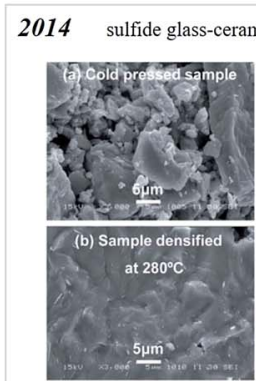

Seino et al. ${ }^{40}$

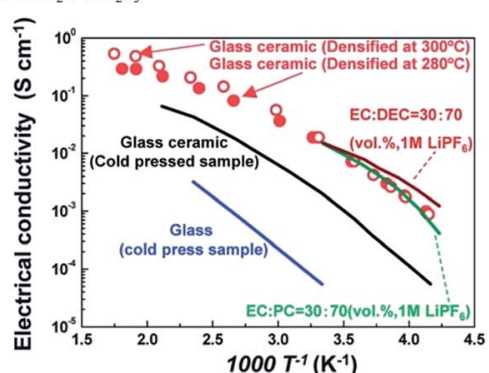

$1000 T^{-1}\left(\mathrm{~K}^{-1}\right)$

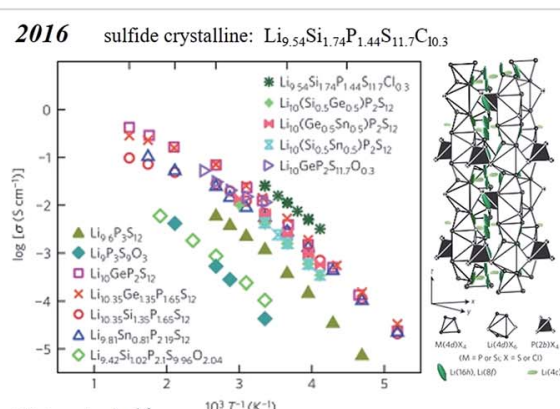

Kato et al. ${ }^{16}$

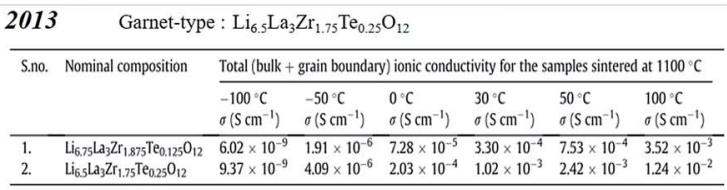

Deviannapoorani et al. ${ }^{29}$

\section{1}

Sulfide glass, $\mathrm{Li}_{2} \mathrm{~S}-\mathrm{P}_{2} \mathrm{~S}_{5}-\mathrm{Lil}$

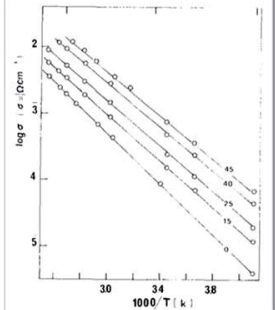

Mercier et al. ${ }^{36}$

\section{6}

1976
Fast $\mathrm{Na}^{+}$conductive behavior in NaSICON type $\mathrm{Na}_{1+\mathrm{x}} \mathrm{Zr}_{2} \mathrm{Si}_{\mathrm{x}} \mathrm{P}_{3-\mathrm{x}} \mathrm{O}_{12}(0 \leq \mathrm{x} \leq 3)$ Goodenough et al. ${ }^{30}$

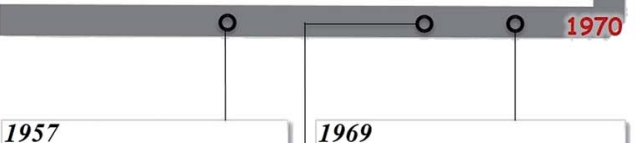

First observation of ionic conductivity of $\mathrm{Li}_{3} \mathrm{~N}$ Masdupuy et al. ${ }^{23}$
1990
NaSICON-type $\mathrm{Li}_{1+\mathrm{x}} \mathrm{M}_{\mathrm{x}} \mathrm{Ti}_{2 \mathrm{x}}\left(\mathrm{PO}_{4}\right)_{3}(\mathrm{M}=\mathrm{Al}, \mathrm{Sc}, \mathrm{La})$

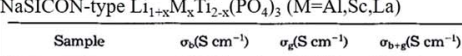

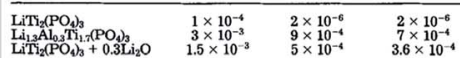
Aono et al. ${ }^{32}$

1986

$\mathrm{NaSICON}$-type $\mathrm{LiTi}_{2}\left(\mathrm{PO}_{4}\right)_{3}$ with the ionic conductivity of $2 \times 10^{-6} \mathrm{~S} \cdot \mathrm{cm}^{-1}$ Subramanian et al. ${ }^{31}$

\section{9}

First Li involved garnet-type $\mathrm{Li}_{3} \mathrm{M}_{2} \mathrm{Ln}_{3} \mathrm{O}_{12}(\mathrm{M}=\mathrm{W}, \mathrm{Te})$ Kasper et al. ${ }^{27}$

1967

Confirmation of perovskite structure of $\mathrm{Ln}_{1 / 3} \mathrm{NbO}_{3}(\mathrm{Ln}=\mathrm{La}, \mathrm{Ce}, \mathrm{Pr}, \mathrm{Nd})$ Iyer et al. ${ }^{24}$

\section{(1)}

2011

011 sulfide crystalline:

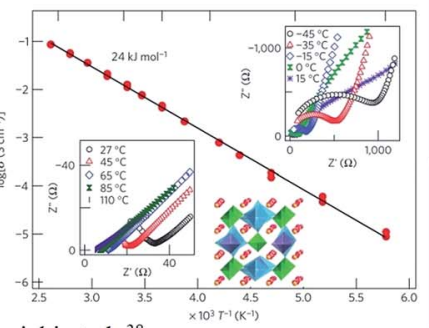

Noriaki et al. ${ }^{38}$

\section{$\infty$}
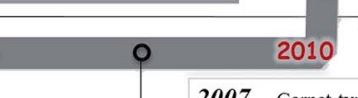

\section{0}

2001 sulfide crystalline, $\mathrm{Li}_{4-\mathrm{x}} \mathrm{Ge}_{1-\mathrm{x}} \mathrm{P}_{\mathrm{x}} \mathrm{S}_{4}$

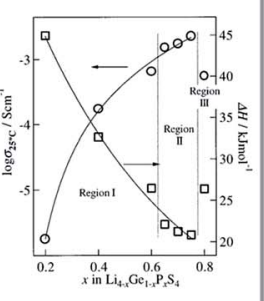

Kanno et al. ${ }^{37}$

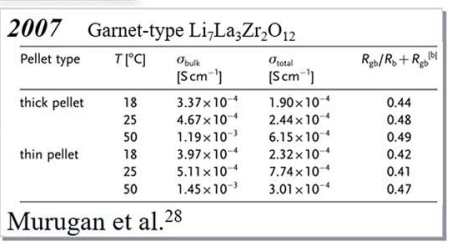
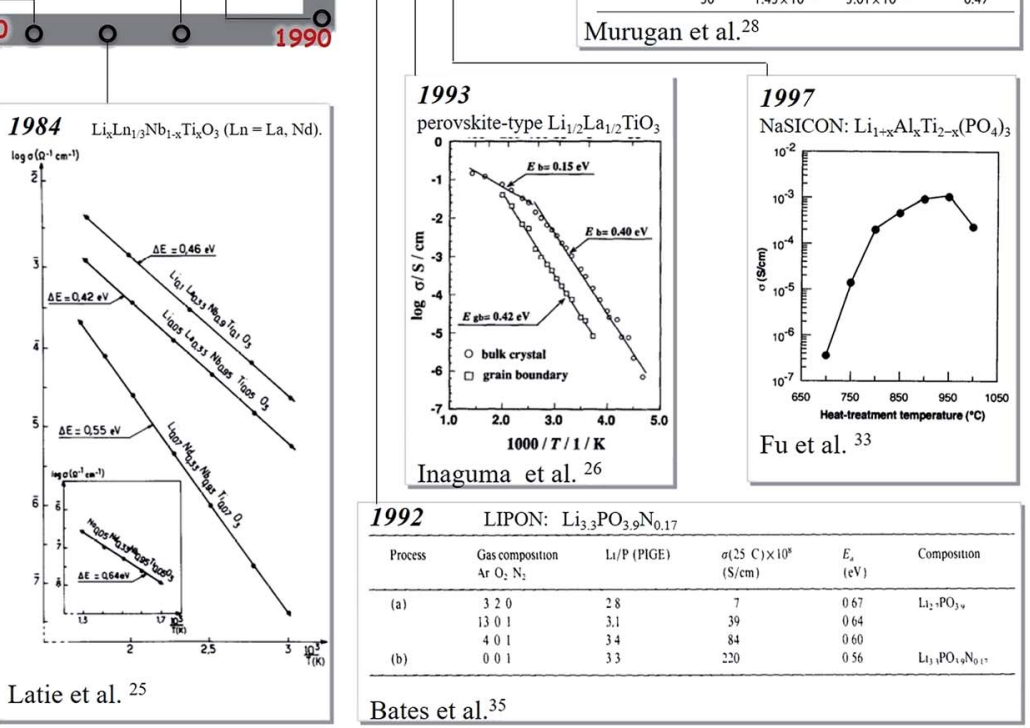

Fig. 2 Historical development of solid state inorganic electrolytes for LIBs.

\section{Attainable specific gravimetric and volumetric energy density of all solid state lithium ion batteries}

ASSLIBs are one of the ultimate solutions to resolve the intrinsic shortcomings faced in current commercial LIBs using liquid electrolytes (e.g. flammability, low lithium transport number, complex reactions at the solid/liquid interfaces, and thermal instability), owing to their attractive attributes, such as excellent safety, much improved specific and volumetric energy densities, ability to achieve both high energy and power densities, etc. Elaborate design of an all-solid-state battery (SSE-separator thickness, SSE ratio in the cathode, anode excess amount, $\mathrm{Li}$ 
metal protection, etc.), however, is needed to achieve improved energy densities, to compete with commercial LIBs. In the following part we will numerically analyze how these design parameters influence the attainable cell-level energy densities of an all-solid-state Li-ion battery, and to what extent the improvement in energy densities can be attained with the optimized parameters. The gravimetric $\left(E_{\mathrm{S}}\right)$ and volumetric $\left(E_{\mathrm{V}}\right)$ energy densities for conventional LIBs and ASSLIBs can be estimated based on the Faradaic theory, and the equations are ${ }^{\mathbf{4 1}}$

$$
E_{\mathrm{S}}=\frac{C_{\mathrm{A}} m_{\mathrm{A}} \bar{V}_{\mathrm{A}}}{\sum w_{\mathrm{i}}}
$$

and

$$
E_{\mathrm{V}}=\frac{C_{\mathrm{A}} m_{\mathrm{A}} \bar{V}_{\mathrm{A}}}{\sum w_{\mathrm{i}} / \rho_{\mathrm{i}}},
$$

where $C_{\mathrm{A}}, m_{\mathrm{A}}, \bar{V}_{\mathrm{A}}, w_{\mathrm{i}}$, and $\rho_{\mathrm{i}}$ are the active material capacity (mA $\left.\mathrm{h} \mathrm{g}^{-1}\right)$, active material loading $\left(\mathrm{g} \mathrm{cm}^{-2}\right)$, average operating voltage $(V)$, weight of individual cell components $\left(\mathrm{g} \mathrm{cm}^{-2}\right)$, and density of individual cell components $\left(\mathrm{g} \mathrm{cm}^{-3}\right)$, respectively. The calculations here only compare the cell-level energy densities, without the battery pack assemblies (such as packaging or the current tabs) which should be similar for LIBs and ASSLIBs. Kinetic or transport limitations are not considered in the calculations, and we simply assume a $100 \%$ utilization of the active materials and a constant average cell operating voltage. A $20 \%$ excessive capacity in Li-metal and graphite anodes is used. It is worth mentioning that, for most of the cathode materials in the discharged state (containing $\mathrm{Li}^{+}$), $\mathrm{Li}$ metal anode is still incorporated in ASSLIBs, which can act as an epitaxial substrate for $\mathrm{Li}$ deposition (charging), improve the interfacial contact, and ensure a full utilization of cathode capacity due to the low coulombic efficiency of the Li metal anode. Meanwhile, the incorporation of the Li metal anode has a minor effect on the total energy densities of the ASSLIB $(<5 \%)$ due to its high capacity. The active material used in the calculations is $\mathrm{NCA}\left(\mathrm{LiNi}_{0.7} \mathrm{Co}_{0.15} \mathrm{Al}_{0.15} \mathrm{O}_{2}\right)$ with a capacity of $200 \mathrm{~mA} \mathrm{~h}$ $\mathrm{g}^{-1}$ and an average voltage of $3.6 \mathrm{~V}$ vs. $\mathrm{Li}^{+} / \mathrm{Li}$. The current collectors used for the cathode and anode are $10 \mu \mathrm{m} \mathrm{Al}$ foil and $5 \mu \mathrm{m} \mathrm{Cu}$ foil, respectively. We can reduce the Al foil thickness by $50 \%$ and remove the anode current collector in ASSLIBs to further improve the energy densities, as will be discussed below. The details about the components of LIBs and ASSLIBs are listed in Table 1 below.
For the LIB with a liquid electrolyte, we consider that the electrolyte completely fills all porosities in the cathode $(40 \%)$, anode (30\%), and separator (50\%), and no additional volume is assumed for the liquid electrolyte. The NCA loading in the cathode $(\mathrm{NCA} / \mathrm{CB}$ (carbon black)/binder $=95 / 2 / 3$ in mass ratio) is $\sim 15 \mathrm{mg} \mathrm{cm}^{-2}$ and the cathode thickness is $\sim 60 \mu \mathrm{m}$. The anode contains $95 \mathrm{wt} \%$ graphite and $5 \mathrm{wt} \%$ binder. The calculated LIB cell attains the specific gravimetric and volumetric energy densities of $\sim 264 \mathrm{~W} \mathrm{~h} \mathrm{~kg}^{-1}$ and $640 \mathrm{~W} \mathrm{~h} \mathrm{~L}^{-1}$, respectively, both comparable to previously reported values. ${ }^{41,42}$ For the ASSLIB, the separator and liquid electrolyte in the LIB are substituted by a SSE layer, and the graphite anode is substituted by Li-metal. We assume $15 \mathrm{wt} \%$ SSE (for a garnet, and this value varied with SSE with different densities to maintain the active material loading and cathode thickness) and $5 \mathrm{wt} \% \mathrm{CB}$ in the cathode to provide good ionic and electronic conduction, and also $10 \%$ porosity in the cathode and anode to account for practical reality, respectively. Three typical SSEs, cubic garnet $\mathrm{Li}_{7} \mathrm{La}_{3} \mathrm{Zr}_{2} \mathrm{O}_{7}$ (LLZO, cubic phase, $\rho \sim 5 \mathrm{~g} \mathrm{~cm}^{-3}$ ), $\mathrm{Li}_{1+x} \mathrm{Al}_{x} \mathrm{Ti}_{2-x^{-}}$ $\left(\mathrm{PO}_{4}\right)_{3}$ (LATP, $\rho \sim 3 \mathrm{~g} \mathrm{~cm}^{-3}$ ), and $\mathrm{Li}_{10} \mathrm{GeP}_{2} \mathrm{~S}_{12}$ (LGPS, $\rho \sim 2 \mathrm{~g}$ $\mathrm{cm}^{-3}$ ), are used to evaluate the effects of SSE separator thickness and mass density on cell energy densities. A schematic of an ASSLIB cell is shown in Fig. 3a. Here we use $5 \mu \mathrm{m} \mathrm{Cu}$ foil (anode) and $10 \mathrm{~mm} \mathrm{Al}$ foil (cathode) as current collectors.

As shown in Fig. 3b, for a constant active material loading of $19.5 \mathrm{mg} \mathrm{cm} \mathrm{cm}^{-2}$ and a cathode thickness of $60 \mu \mathrm{m}$, to achieve improved energy densities, the thickness of the SSE separator in ASSLIB must be less than a critical value, which can be called the break-even thickness (BET). For instance, the BET for $E_{\mathrm{S}}$ of LLZO, LATP, and LGPS are $\sim 41 \mu \mathrm{m}, \sim 74 \mu \mathrm{m}$, and $\sim 115 \mu \mathrm{m}$, respectively. It is obvious that the SSE with a smaller mass density shows a larger BET and is practically easier to achieve a high $E_{\mathrm{S}}$. To obtain better $E_{\mathrm{V}}$, a SSE separator less than $120 \mu \mathrm{m}$ in thickness is necessary. Due to the assumption of the same active material loading and cathode thickness, the BETs of $E_{\mathrm{V}}$ for different SSEs (in mass density) are the same. Without considering the kinetic issues (ionic conductivity, space charge layer, etc.) and chemical compatibility (inter-diffusion and chemical reactions) between the SSE and electrode materials, using a SSE with a smaller mass density, such as $\mathrm{Li}_{2} \mathrm{~S}-\mathrm{P}_{2} \mathrm{~S}_{5}$ glass or LGPS, it is easier to achieve higher energy densities and thus is more attractive for ASSLIBs. For instance, to achieve a 50\% improvement in $E_{\mathrm{S}}$ for the $60 \mu \mathrm{m}$ thick cathode $\left(\sim 19.5 \mathrm{mg} \mathrm{cm}^{-2}\right.$ loading), a thickness of $\sim 5 \mu \mathrm{m}$ is needed for LLZO which is

Table 1 Parameters used for the calculations of energy densities of LIBs and ASSLIBs (based on a garnet solid electrolyte with a mass density of $\sim 5 \mathrm{~g} \mathrm{~cm}^{-3}$ )

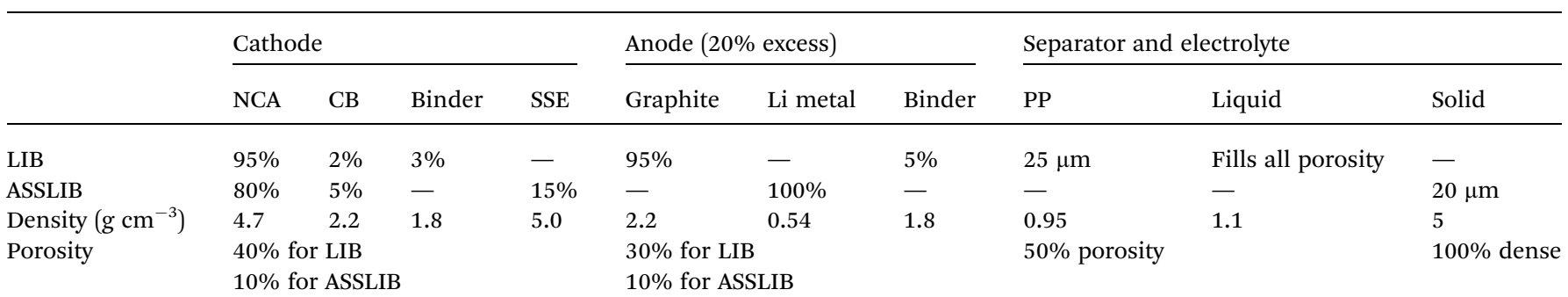



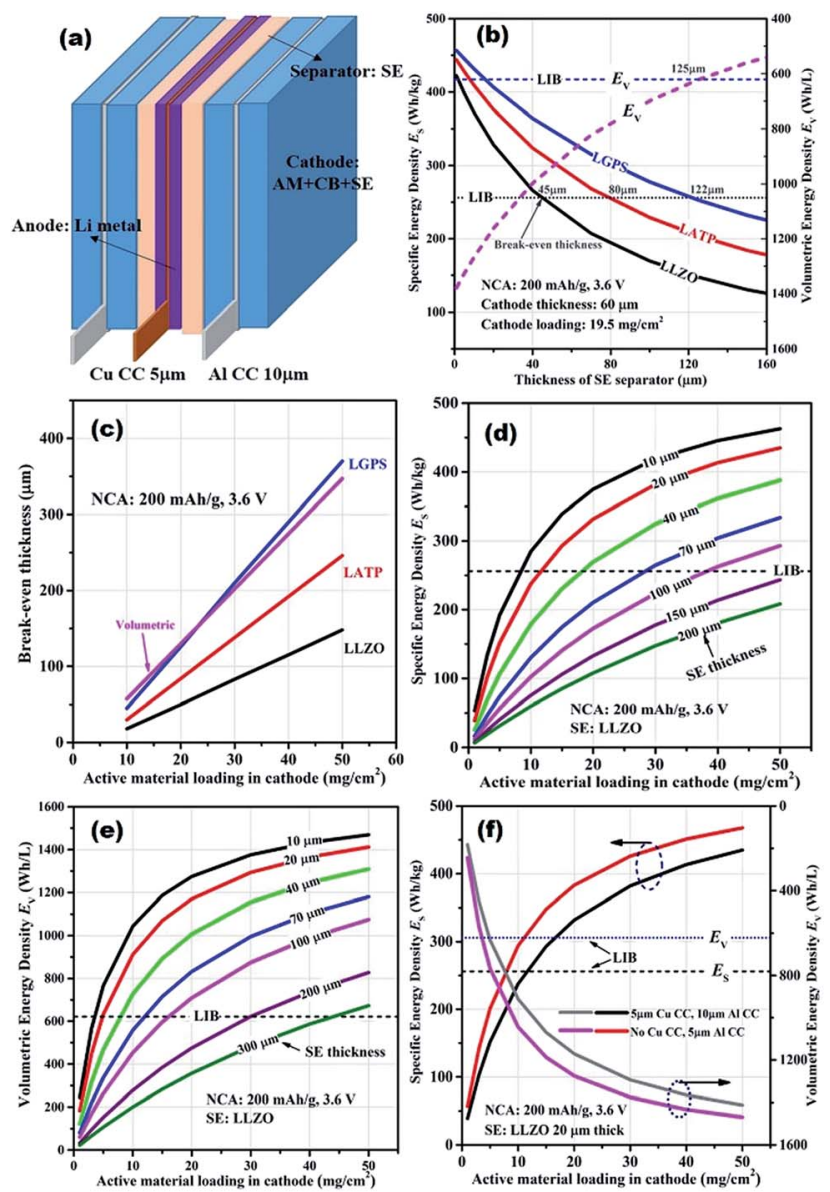

Fig. 3 The calculations of attainable energy densities of ASSLIBs compared with the conventional LIB using liquid electrolytes. (a) Schematic of a cell core in ASSLIBs; (b) specific gravimetric and volumetric energy densities of ASSLIBs as functions of SSE separator thickness for three different SSEs, here the active material (NCA) loading and thickness of the cathode are fixed at $19.5 \mathrm{mg} \mathrm{cm}^{-2}$ and $60 \mu \mathrm{m}$, respectively; (c) the break-even thickness for specific gravimetric and volumetric energy densities as functions of active material loading for three different SSEs; (d) specific energy densities for ASSLIBs with different SSE separator (LLZO) thicknesses as functions of active material loading; (e) volumetric energy densities for ASSLIBs with different SSE separator (LLZO) thicknesses as functions of active material loading; ( $f$ ) comparison of the energy densities for ASSLIBs with normal ( $5 \mu \mathrm{m}$ Cu and $10 \mu \mathrm{m}$ Al foils) and modified (no Cu and $5 \mu \mathrm{m}$ Al foil) current collectors as a function of active material loading.

technically very challenging, but for LGPS this value increases to $\sim 24 \mu \mathrm{m}$, which is technically more feasible. In addition, the BET is found to be a linear function of the active material loading and thus the cathode thickness (also cell capacity), as shown in Fig. 3c. This is mainly due to the required simultaneous increase in the thickness of the anode, which increases the volume and thickness difference between $\mathrm{Li}$ metal and graphite anodes, and thus extends the thickness limitation on SSE. For example, an active material loading of $10 \mathrm{mg} \mathrm{cm} \mathrm{cm}^{-2}$ needs a BET of $\sim 16 \mu \mathrm{m}$ while $50 \mathrm{mg} \mathrm{cm}^{-2}$ loading increases the BET to $135 \mu \mathrm{m}$ for LLZO. The lighter LGPS shows a much higher BET of $E_{\mathrm{S}}$ as compared with LLZO, especially at high active material loadings.
Excessive amount of $\mathrm{Li}$ has a very little effect on $E_{\mathrm{S}}$ and a modest influence on $E_{\mathrm{V}}$, and thus the excess amount of $\mathrm{Li}$ anode is not optimized in the simulation. Compared with the BET of $E_{\mathrm{S}}$, the BET of $E_{\mathrm{V}}$ shows relatively smaller variations, mainly due to the small porosity in ASSLIBs and utilization of high energy density Li metal.

Take LLZO as an example which shows a decently high Liionic conductivity and excellent stability in contact with $\mathrm{Li}$ metal. Fig. 3d and (e) show the specific and volumetric energy densities as functions of active material loading of cells with different SSE layer thicknesses. $E_{\mathrm{S}}$ increases gradually with increasing active material loading, but reaches an asymptotic limit at a given SSE separator thickness. It is obvious that using the cell with a thinner SSE separator it is easy to achieve superior energy densities compared to LIBs with liquid electrolytes. As shown in Fig. 3d, a LLZO separator thicker than $150 \mu \mathrm{m}$ hardly achieves an improved $E_{\mathrm{S}}$. Meanwhile, it is relatively easy to obtain an improved volumetric energy density for ASSLIBs $v s$. LIBs. This is also due to the high energy density of Li metal $v s$. graphite, and much smaller porosities in electrodes and separators in ASSLIBs. For a $100 \mu \mathrm{m}$ thick SSE separator, loading of $17 \mathrm{mg} \mathrm{cm}^{-2}$ or more active material could achieve a superior $E_{\mathrm{V}}$, and this amount of active material is comparable to commercial LIBs. Considering both $E_{\mathrm{S}}$ and $E_{\mathrm{V}}$, fabrication of a dense and highly conductive SSE separator with a thickness of less than 50 $\mu \mathrm{m}$ is desirable, although it is technically very challenging.

For packed ASSLIBs, the anode current collector $(5 \mu \mathrm{m} \mathrm{Cu}$ foil) can be removed by employing Li metal as both the anode and the current collector, and the usage of the cathode current collector $(10 \mu \mathrm{m} \mathrm{Al}$ foil) can be reduced by $50 \%$, as shown in Fig. 3a. Fig. 3f shows the comparison of energy densities for ASSLIBs with the same current collectors as LIBs $(5 \mu \mathrm{m} \mathrm{Cu}$ and $10 \mu \mathrm{m} \mathrm{Al} \mathrm{foils)} \mathrm{and} \mathrm{modified} \mathrm{current} \mathrm{collectors} \mathrm{(no} \mathrm{Cu}$ and $5 \mu \mathrm{m}$ $\mathrm{Al}$ foil) as a function of the active material loading. The SSE separator is a $20 \mu \mathrm{m}$ thick LLZO. The deduction in the usage of current collectors can modestly improve the attainable energy densities. The improvement percentage decreases from $\sim 46 \%$ to $7 \%$ for $E_{\mathrm{S}}$, and from $34 \%$ to $4 \%$ for $E_{\mathrm{V}}$ with increasing active

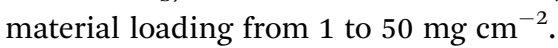

The above numerical analysis provides some fundamental guidance for designing ASSLIBs, which are still in their infancy and need significant efforts to tackle the scientific and technical challenges. Besides the aforementioned factors, the amount of SSE in a composite cathode is another factor needed to be considered. For most of the reported ASSLIBs, the SSE loading in the cathode is usually more than $30 \mathrm{wt} \%$ to ensure the ionic conduction and good structural compatibility with the SSE separator. A large SSE loading will definitely decrease the energy densities and put more restricted limitations on the thickness of the SSE separator and active materials loading (thickness of the cathode), which thus place more challenges in cell fabrication and operations at high current densities.

Another critical issue in ASSLIBs is the mechanical properties of solid electrolyte separators (such as the elastic modulus and densification behavior), both in the fabrication and operation of ASSLIBs. The sulfide SSEs with good ductility are easily integrated into the bulk batteries by cold pressing, whereas the 
ceramic nature (stiffness and brittleness) of oxide SSEs, such as LLTO, LLZO, LATP, etc., poses a critical restriction for the fabrication of bulk-type ASSLIBs. ${ }^{43}$ A sintering process at elevated temperatures, rather than cold pressing, is generally necessary but will generate unwanted interfacial layers, resulting in a large interfacial resistance and failure of bulk-type ASSLIBs. In this respect, sulfide SSEs with higher ionic conductivity and better ductility are more favorable than the oxides. $^{\mathbf{4 3 , 4 4}}$

Moreover, another critical consideration for large-scale applications of ASSLIBs is the cost, including materials and fabrication costs. As suggested by McClosky, ${ }^{41}$ a cost of 10 \$ per $\mathrm{m}^{2}$ is imperative for a SSE separator to compete with conventional LIBs, and this is an extremely aggressive cost goal for inorganic Li-ion conductors, particularly when combined with the likely high processing costs. However, the advantages of high energy densities and excellent safety provided by ASSLIBs may find applications where high costs can be tolerated.

\section{Interfacial behaviours of $\mathrm{Li}^{+}$ conductors in various battery systems}

In general, ideal Li-ion conductors used in any battery system should have the attributes of (1) high ionic conductivity enabling the solid-state batteries to work at high rates and wide temperature range, (2) good electrochemical compatibility with a high energy density cathode (e.g., NCM, NCA) and anode (Li metal), (3) low interfacial resistance and stable interfacial performance between SSE/electrode materials and SSE/SSE interfaces, (4) minimal inter-diffusion and side reactions between the electrodes and SSE. Other requirements include good mechanical strength and cost-effective synthesis and integration approaches. Most of the reported work on SSE has been focusing on increasing the bulk conductivity, although the interface impedance is more challenging in most applications. For example, Table 2 uses data from ref. 18 which compare the ion conductivity, band gap, and maximum SSE thickness for four most popular SSEs, one of which shows ionic conductivity greater than $1 \mathrm{mS} \mathrm{cm}{ }^{-1}$ for Li-ions at room temperature. ${ }^{45}$ The

Table 2 Measured Li-ion conductivities, $\sigma_{\mathrm{Li}^{+}}$, band gaps, $\Delta E_{\mathrm{g}^{\prime}}$ and maximum SSE thickness, $d_{\mathrm{be}}$, and $d_{1.5 * \mathrm{be}}$ for four SSEs. * Reprinted from ref. 18 with permission. Copyright 2015 American Chemical Society. * The LiPON, LGPS, and $\mathrm{Li}_{3} \mathrm{ClO} \Delta E_{\mathrm{g}}$ were estimated from DFT calculations using the HSEO6 or related functional, and the C-LLZO $\Delta E_{\mathrm{g}}$ was obtained from optical experiments. $d_{\mathrm{be}}$ is the break-even SSE thickness for a Li|SSE|C battery to reach parity in specific energy with a conventional liquid Li-ion cell appropriate for a vehicle battery, as described in McCloskey. ${ }^{46} d_{\mathrm{be} * 1.5}$ is the SSE thickness required for a $50 \%$ increase in specific energy relative to the conventional liquid $\mathrm{Li}-$ ion cell

\begin{tabular}{lllll}
\hline SSE & $\sigma_{\mathrm{Li}} @ 300 \mathrm{~K}\left(\mathrm{~S} \mathrm{~cm}^{-1}\right)$ & $\Delta E_{\mathrm{g}}(\mathrm{eV})$ & $d_{\mathrm{be}}(\mathrm{nm})$ & $d_{1.5 * \mathrm{be}}(\mathrm{nm})$ \\
\hline LiPON & $2 \times 10^{-6}$ & $\sim 6$ & 69 & 12 \\
c-LLZO & $(2-3) \times 10^{-4}$ & $\sim 5.1$ & 34 & 6 \\
LGPS & $1.2 \times 10^{-2}$ & 3.6 & $\sim 80$ & 14 \\
Li $_{3} \mathrm{ClO}$ & $8.5 \times 10^{-4}$ & 6.4 & $\sim 80$ & 14
\end{tabular}

SSE thickness cannot exceed a few tens of microns if the energy density of ASSLIBs is targeted to compete with or outperform that of liquid LIBs, as suggested in the analyses above and Table 2. Meanwhile, it is interesting to note a recent breakthrough in lithium superionic conductors with an exceptionally high conductivity of $25 \mathrm{mS} \mathrm{cm}{ }^{-1}$ for $\mathrm{Li}_{9.54} \mathrm{Si}_{1.74} \mathrm{P}_{1.44} \mathrm{~S}_{11.7} \mathrm{Cl}_{0.3}{ }^{16}$ An extremely high power $\mathrm{Li}_{4} \mathrm{Ti}_{5} \mathrm{O}_{12} / \mathrm{SSE} / \mathrm{LiCoO}_{2}$ battery has been demonstrated by using a $240 \mu \mathrm{m}$ thick electrolyte membrane. Although the authors did not provide detailed information on addressing the interfacial impedance issues of the cell containing such a thick SSE separator, the results are very encouraging for the commercialization of all-solid-state Li-ion batteries. Instead of covering all kinds of SSEs, in the following part we select a few representative SSEs and discuss their interfacial behaviors in different battery systems. Emphasis will be placed on the origin of interfacial impedance, interactions between SSE and electrode materials during repeated cycling, and the failure mechanism of interfacial conductivity.

\subsection{SSE/electrode interfaces in Li-ion batteries}

The interfacial phenomena that impede the Li-ion conduction mainly include lattice mismatch, space charge regions, formation of interphases, and the "compatibility" of lithium metal with the SSE surface. ${ }^{47}$ Although these interfaces play dominant roles in deteriorating the power capabilities of ASSLIBs, they have attracted less attention as compared to the reported studies on improving bulk ionic conductivity in SSEs. The crystal structure lattice mismatch, ${ }^{48}$ the existence of an $\mathrm{Li}^{+}$ deficient space charge layer in $\mathrm{SSE}^{49}$ and the formation of interphases $^{50}$ are the main origins of high impedances at the SSE/cathode interfaces, which hence also contribute significantly to the impedance of the whole cell ${ }^{\mathbf{1 8}}$ and will be discussed in detail as follows. The "compatibility" of lithium metal with the SSE surface will be separately discussed later in this review.

Lattice mismatch. Lattice mismatch refers to the mismatch between SSE grain boundaries and the mismatch between the cathode material and SSE. Chi et al. directly observed the significant structural and chemical deviation at the grain boundaries of the superionic conductor $\left(\mathrm{Li}_{3 x} \mathrm{La}_{2 / 3-x}\right) \mathrm{TiO}_{3}$ (LLTO) by conducting atomic-resolution Scanning Transmission Electron Microscopy/Electron Energy Loss Spectroscopy (STEM/EELS) analysis (Fig. 4). ${ }^{48}$

In order to compensate for the random orientation of adjacent grains, the structural and chemical deviation is unavoidable on the boundaries, which is not energetically favorable for $\mathrm{Li}^{+}$transport, giving rise to the high "grain-boundary" resistance. Meanwhile, the compatibility between the SSE and cathode material also critically influences the interfacial resistance. The volume changes in an oxide cathode such as $\mathrm{LiCoO}_{2}$ releases the stress at the interface between amorphous- $\mathrm{LiCoO}_{2}$ and the $\mathrm{Li}_{2} \mathrm{O}-\mathrm{Al}_{2} \mathrm{O}_{3}-\mathrm{P}_{2} \mathrm{O}_{5}-\mathrm{TiO}_{2}$-based glass-ceramic solid electrolyte (LATP-GC electrolyte) and causes large $\mathrm{Co}-\mathrm{O}$ bond changes. Inactive $\mathrm{Co}_{3} \mathrm{O}_{4}$ (for the charge transfer reaction) was found at the interface, decreasing the number of interfacial active sites for charge transfer and increasing the interfacial impedance. The addition of a buffer layer such as $\mathrm{NbO}_{2}$ in 

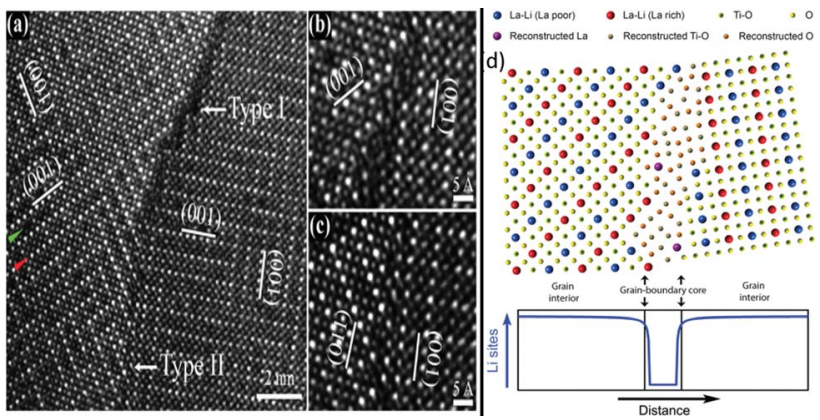

Fig. 4 (a) High Angle Annular Dark Field/Scanning Transmission Electron Microscopy (HAADF-STEM) image of a grain boundary (GB) exhibiting both dark- and normal-contrast regions, labelled as Type I and Type II, respectively. Within the grains, a row of atomic columns for a La-poor layer and one for a La-rich layer are indicated by green and red arrows on the left hand side of the image, respectively. The planes of the alternating La-rich/La-poor layers (arbitrarily designated as (001) planes in the image) of different regions in the grain are marked to highlight the existence of nanodomains. (b) Further magnified Type I GB feature. (c) Further magnified Type II GB feature. (d) Schematic of the atomic configuration of the Type I GB based on the HAADF-STEM images and EELS analysis, along with an illustration of the Li site distribution across the Type I GB. ${ }^{48}$ Reprinted from ref. 48 with permission. Copyright 2015 Energy \& Environmental Science.

between converts $\mathrm{Co}_{3} \mathrm{O}_{4}$ into $\mathrm{LiNbO}_{3}$ and $\mathrm{LiCoO}_{2}$ and restricts the abrupt changes in the $\mathrm{Co}-\mathrm{O}$ bond at the interface during delithiation. ${ }^{51}$

During cycling, the lithiation-induced volume change is also expected to induce lattice mismatch between the electrode and electrolyte. The ionic mass transfer in and out of the anode and cathode materials during charge/discharge results in volume changes in the electrodes that can rapidly disrupt the mechanical integrity of both the electrode structure and the electrode-electrolyte interfaces. For most of the commercialized intercalation electrode materials, relatively small volume changes $<10 \%$ can be observed during lithiation, such as $\sim 6-$ $10 \%$ for graphite, ${ }^{52} \sim 3 \%$ for $\mathrm{LiCoO}_{2}, \sim 6.6 \%$ for $\mathrm{LiFePO}_{4},{ }^{53} 6.5 \%$ for spinel $\mathrm{LiMn}_{2} \mathrm{O}_{4}$, and $\sim 2-6 \%$ for NMC (depending on $\mathrm{Ni}$ content). ${ }^{54}$ These relatively small volume changes $(<10 \%)$, however, can be mitigated to a large extent by refining the grains, controlling the porosity, adding ductile components, modifying the cell structure, etc. So for the intercalation electrode materials, the lithiation-induced volume expansion can be well controlled to ensure good cycling stability, as shown in many recent studies. ${ }^{\mathbf{1 0 , 1 6 , 5 5}}$ It is also noted that SSEs with small elastic moduli, such as sulfides, can effectively accommodate the volume changes by elastic deformation during the lithiation/delithiation processes. Furthermore, the ductile Li anode can also act as the current collector and Li deposition substrate during charging. To ensure intimate contact of Li/SSEs during the long time cycling of the cell, external pressure is usually needed, which will sacrifice the energy density and increase the cost. A framework structure for the $\mathrm{Li}$ metal anode may be another option to host the Li-deposition, and thus maintain the cell structure and intimate contacts. To fully understand and mitigate the volume changes of ASSLIBs during charging/ discharging, in situ experimental techniques and theoretical modeling need to be developed.

Space charge regions. If a sulfide-based electrolyte is used, the lattice mismatch should not be a significant problem because the sulfide is soft and easily builds the interface connection. ${ }^{15}$ However, large interfacial resistance was still observed, although sulfide-type SSEs have been reported to have comparable ionic conductivity with those of liquid organic electrolytes. ${ }^{15,40}$ An interposed buffer layer is usually required to reduce the cathode/SSE impedance..$^{\mathbf{1 0}, 49,56-58}$ This universal phenomenon has been explained by using the space charge layer mechanism. ${ }^{59,60}$ A space charge layer forms in the sulfide side with reduced Li-ion concentration which may decrease the Li-ion conductivity. Simulations revealed that preferred $\mathrm{Li}$ adsorption at the oxygen bridge sites of the oxide, e.g., $\mathrm{CoO}_{6}$, and on the Li layer may be the origin of the deformed interface or space charge layers. The subsurface $\mathrm{Li}$ in the sulfide electrolyte side may move under the electrical field at the interfaces, suggesting that a space charge layer immediately grows at the beginning of charging. Therefore, the observed interfacial resistance was always high. ${ }^{47}$ During the charge process, Li-ions are extracted from $\mathrm{LiCoO}_{2}$, and the $\mathrm{Li}$ rich region on $\mathrm{LiCoO}_{2}$ disappears which further stimulates the growth of space charge layers. The interposition of $\mathrm{LiNbO}_{3}$ forms smooth interfaces without $\mathrm{Li}$ adsorption sites on both oxide cathode $/ \mathrm{LiNbO}_{3}$ and sulfide/LiNbO ${ }_{3}$ interfaces. $\mathrm{LiNbO}_{3}$ suppresses the growth of the space charge layer, while providing alternative diffusion paths for Li-ions. ${ }^{57}$ Fig. 5 compares the Li-ion concentration at the initial stage of charging at the interfaces with and without $\mathrm{LiNbO}_{3}$ buffer layers by DFT calculations. ${ }^{47}$ Note that the space charge layers clearly depend on the applied voltage in DFT calculations and this applied voltage needs to be carefully calibrated to simulate interfaces at the electrochemical equilibrium state. Furthermore, a recent theoretical study highlights the difference between the actual voltage of the cell and that governing the Li ion transport at the interfaces, demonstrating the complications and subtle interplays between the electrons and the ions. This work also begs for detailed studies on the electron-ion interactions at the interfaces, before one could fully control and optimize the interfacial properties in ASSLIBs. ${ }^{61}$

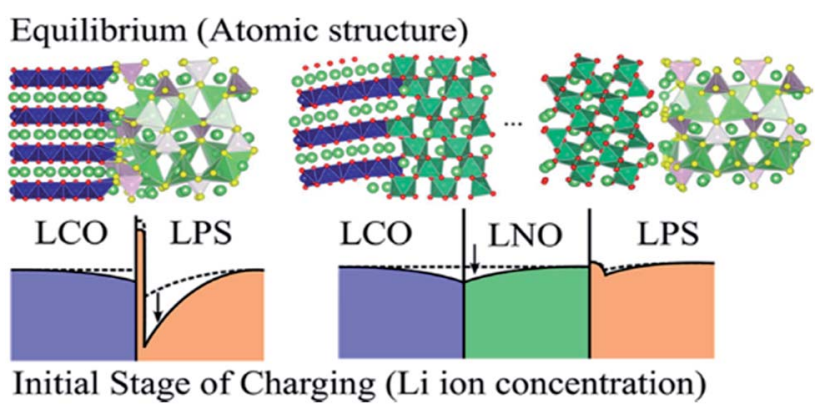

Fig. 5 Comparison of $\mathrm{Li}$-ion concentration at the $\mathrm{LiCoO}_{2}(\mathrm{LCO}) /$ $\mathrm{Li}_{3} \mathrm{PS}_{4}$ (LPS) interfaces without (left) and with (right) the $\mathrm{LiNbO}_{3}$ (LNO) buffer layer. ${ }^{47}$ Reprinted from ref. 47 with permission. Copyright 2014 American Chemical Society. 


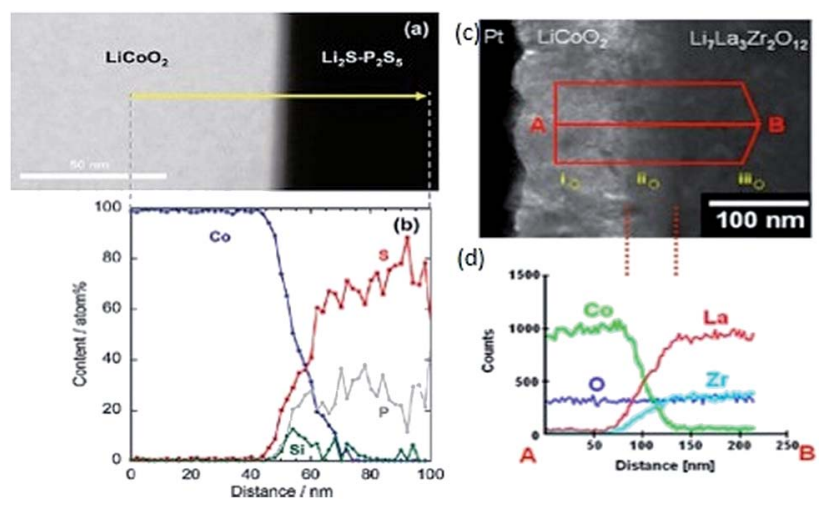

Fig. 6 (a) Cross-sectional HAADF-STEM image of the $\mathrm{Li}_{2} \mathrm{SiO}_{3}$-coated $\mathrm{LiCoO} / \mathrm{Li}_{2} \mathrm{~S}-\mathrm{P}_{2} \mathrm{~S}_{5}$ interface after initial charging, (b) cross-sectional EDX line profiles for Co, P, S, and Si elements. The arrow in (a) indicates the positions of the EDX measurements, ${ }^{50}$ (c) cross-sectional TEM image of a $\mathrm{LLZ} / \mathrm{LiCoO}_{2}$ thin-film interface and (d) the EDS line profile obtained from the region indicated by the arrow in the direction A-B. The broken lines indicate the mutual diffusion layer at the $\mathrm{LLZ} / \mathrm{LiCoO}$ interface. ${ }^{63}$ Reprinted from ref. 50 with permission. Copyright 2010 American Chemical Society. Reprinted from ref. 63 with permission. Copyright 2011 Elsevier.

Inter-diffusion layers. The chemical stability of both oxide cathode and solid electrolyte also affects the interfacial properties between them. For example, at the $\mathrm{LiCoO}_{2} / \mathrm{Li}_{2} \mathrm{~S}-\mathrm{P}_{2} \mathrm{~S}_{5}$ interface, Co diffusion from $\mathrm{LiCoO}_{2}$ to the sulfide side was observed, ${ }^{50}$ while $\mathrm{S}$ and $\mathrm{P}$ elements may also migrate to the $\mathrm{LiCoO}_{2}$ side (Fig. 6a and b). ${ }^{50,62}$ Again, buffer layers such as $\mathrm{Li}_{2} \mathrm{SiO}_{3}$ coating on $\mathrm{LiCoO}_{2}$ effectively suppress the inter-diffusion of Co, P, and S at the electrode/electrolyte interface which improves the electrochemical performances of ASSLIBs. Similarly, at the interface of $\mathrm{LiCoO}_{2}$ thin film/garnet-structured $\mathrm{Li}_{7} \mathrm{La}_{3} \mathrm{Zr}_{2} \mathrm{O}_{12}$, an inter-diffusion layer was also captured (Fig. 6c and d). ${ }^{63}$ Some spots of this interface layer were also found to correspond to the crystal structure of $\mathrm{La}_{2} \mathrm{CoO}_{4}$, which impedes the $\mathrm{Li}^{+}$diffusion. Changing the annealing temperature and the composition of the garnet-type oxide could remove this intermediate layer (Fig. 6) at the LCO/LLZO interface and enhance the chemical and structural stability of the interface during cycling, which leads to very fast $\mathrm{Li}^{+}$transport and thus high power Li-ion batteries. ${ }^{64}$ Another common approach used to modify the interface is the addition of a buffer layer (similar to that used to suppress the space charge layer). From energydispersive X-ray spectroscopy (EDX), there is no significant inter-diffusion layer found in between the $\mathrm{LiNbO}_{3}$-modified $\mathrm{LiCoO}_{2} / \mathrm{Li}_{7} \mathrm{P}_{3} \mathrm{~S}_{11}$ interface. The $\mathrm{LiNbO}_{3}$ buffer layer functions as a passivation layer to prevent the crossover of Co, $\mathrm{S}$, and $\mathrm{P}$ elements through the interface, which is illustrated in Fig. $7 .^{\mathbf{6 5}}$ In addition, the surface properties of the original SSE are also sensitive to the ambient conditions and may induce a foreign phase on the SSE, which will affect the Li conduction. Doeff et al. reported that exposure of LLZO (Al-substituted $\mathrm{Li}_{7} \mathrm{La}_{3} \mathrm{Zr}_{2}$ $\mathrm{O}_{12}$ ) to the air leads to the formation of $\mathrm{a} \mathrm{Li}_{2} \mathrm{CO}_{3}$ layer on the LLZO surface, which could also contribute to the interfacial resistance. Surface polishing on LLZO removed $\mathrm{Li}_{2} \mathrm{CO}_{3}$ and led to the substantial decrease of interfacial impedance. ${ }^{66}$

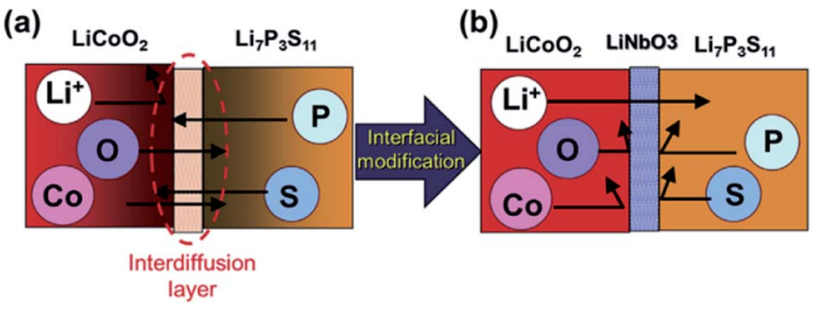

Fig. 7 Schematic images of the $\mathrm{LiCoO}_{2} / \mathrm{Li}_{7} \mathrm{P}_{3} \mathrm{~S}_{11}$ interface (a) without and (b) with a modified layer. ${ }^{65}$ Reprinted from ref. 65 with permission. Copyright 2014 Elsevier.

The chemical and electrochemical stabilities of solid electrolyte-electrode interfaces in ASSLIBs are also studied in detail in recent calculations. ${ }^{67-71}$ Most SSEs have limited electrochemical windows from first-principle calculations, and are thermodynamically unstable against cathode materials and $\mathrm{Li}$ metal. Thus the chemical reactions and decompositions of SSEs generally happen at the interfaces. ${ }^{69,71}$ The experimentally observed outstanding stability of SSEs is mainly due to the sluggish kinetics of the decomposition reactions. To ensure stable interfaces and cycling of ASSLIBs, effective in situ or ex situ passivation interfaces with good ionic conduction and electronic insulation are required to prevent further chemical reactions at SSE-electrode interfaces and decompositions of the SSE. One successful example is the excellent in situ passivation of thiophosphate, e.g., $\mathrm{Li}_{2} \mathrm{~S}-\mathrm{P}_{2} \mathrm{~S}_{5}$ glass, in contact with Li metal, in which the reduced products $\mathrm{Li}_{2} \mathrm{~S}, \mathrm{Li}_{3} \mathrm{P}$, and $\mathrm{Li}_{2} \mathrm{O}$ are electronic insulators and decent ionic conductors. ${ }^{71,73}$ However, SSEs that contain Ge (LGPS and LAGP) or Ti (LLTO and LATP) are normally unstable with $\mathrm{Li}$ due to the formation of electronically conductive LiGe alloys and Li titanates. ${ }^{71,73}$ For these SSEs, as mentioned above, surface coating of either electrode materials or SSEs is necessary to passivate the interfaces.

\subsection{Interfacial challenges in all-solid-state $\mathrm{Li}-\mathrm{S}$ batteries}

$\mathrm{Li}-\mathrm{S}$ batteries have been considered as one of the most promising next-generation battery technologies with a potential of possessing energy densities at least twice those of state-of-theart Li-ion batteries. ${ }^{72}$ However, the intermediate reaction products polysulfides, especially the long-chain ones, easily dissolve in the liquid electrolyte causing "shuttle reactions" and "contaminations" everywhere in the cell. The end result is fast capacity degradation, low columbic efficiency, severe selfdischarge, etc. ${ }^{73-75}$ SSE has been proposed to prevent sulfur dissolution.

Tatsumisago et al. firstly reported the use of a sulfide-based SSE $\left(80 \mathrm{Li}_{2} \mathrm{~S} \cdot 20 \mathrm{P}_{2} \mathrm{~S}_{5}\right.$ glass-ceramic obtained by mechanical milling) for solid state $\mathrm{Li}-\mathrm{S}$ batteries. At room temperature, good electrochemical performances have been demonstrated. It has been noted that $\mathrm{Cu}$ is milled with $\mathrm{S}$ during the preparation process of the cathode. CuS is produced after milling which is also electrochemically active. ${ }^{76}$ A capacity of $650 \mathrm{~mA} \mathrm{~h} \mathrm{~g}$ (based on the total weight of $\mathrm{S}$ and $\mathrm{Cu}$ ) was delivered at a low current density of $0.064 \mathrm{~mA} \mathrm{~cm}^{-2}$ with a discharge cutoff voltage 
at $0.3 \mathrm{~V}$. Fine powders prepared by mechanical milling were believed to form intimate contact between the SSE and $\mathrm{S} / \mathrm{Cu}$ cathode and the feasibility of building rechargeable all-solidstate $\mathrm{Li}-\mathrm{S}$ batteries was demonstrated. A thio-LISICON $\left(\mathrm{Li}_{3.25^{-}}\right.$ $\mathrm{Ge}_{0.25} \mathrm{P}_{0.75} \mathrm{~S}_{4}$ ) electrolyte was also reported for solid state sulfur batteries. ${ }^{77}$ Without the incorporation of $\mathrm{Cu}$ in the cathode mixtures, a very low capacity of only $120 \mathrm{~mA} \mathrm{~h} \mathrm{~g}^{-1}$ was observed. However, when the authors switched from mechanical milling to gas-phase mixing, the initial discharge capacity was improved to $590 \mathrm{~mA} \mathrm{~h} \mathrm{~g}^{-1}$. The gas-phase mixing process was able to fabricate nanosized particles and enhance the contact between sulfur and the conducting carbon matrix, which plays a key role in the high performance of as-prepared solid sulfur batteries. The AC impedance spectroscopy indicated a low resistivity for the composite electrode fabricated by gas/solid mixing. More recently, a glass-type $75 \mathrm{Li}_{2} \mathrm{~S}-25 \mathrm{P}_{2} \mathrm{~S}_{5}$ (stoichiometric $\mathrm{Li}_{3} \mathrm{PS}_{4}$ ) electrolyte has been applied to develop high
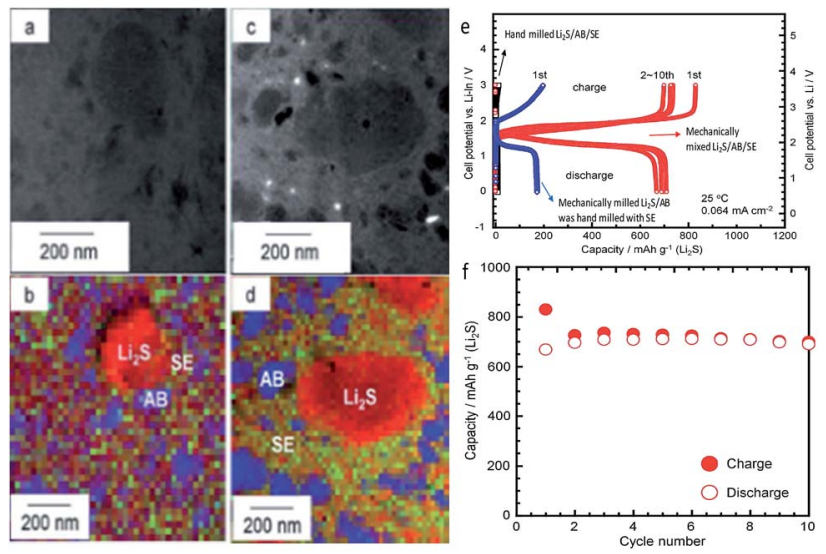

Fig. 8 (a) Cross-sectional HAADF-STEM image and (b) corresponding EELS map for $\mathrm{Li}_{2} \mathrm{~S}$ composite electrodes before a charge-discharge test. (c) Cross-sectional HAADF-STEM image and (d) EELS maps of electrodes after 10 cycles. (e) Charge-discharge curves of all-solidstate cells of $\mathrm{In} / 80 \mathrm{Li}_{2} \mathrm{~S}-2 \mathrm{OP}_{2} \mathrm{~S}_{5}$ glass-ceramic- $\mathrm{Li}_{2} \mathrm{~S}$ with $\mathrm{Li}_{2} \mathrm{~S} / \mathrm{AB} / \mathrm{SSE}$ cathode mixtures treated differently. (f) Cycling stability of the mechanically mixed $\mathrm{Li}_{2} \mathrm{~S} / \mathrm{AB} / \mathrm{SSE}$ cathode at $0.064 \mathrm{~mA} \mathrm{~cm}^{-2}$ at $25^{\circ} \mathrm{C}^{80}$ Reprinted from ref. 65 with permission. Copyright 2012 Royal Society of Chemistry. performance solid Li-S batteries. High columbic efficiency of 99\% was demonstrated with an initial capacity as high as 1600 $\mathrm{mA} \mathrm{h} \mathrm{g}^{-1} .^{78}$

$\mathrm{Li}_{2} \mathrm{~S}$ has also been directly employed as the cathode to diversify the cathode selection for solid state batteries. Cu was found again to help the activation of highly insulating $\mathrm{Li}_{2} \mathrm{~S}$ when added during the mixing process. An amorphous $\mathrm{Li}_{x} \mathrm{CuS}$ domain during the milling process was probably formed, which improves the initial discharge capacity of $\mathrm{Li}_{2} \mathrm{~S}$ to $\sim 490 \mathrm{~mA} \mathrm{~h} \mathrm{~g}^{-1}$ during the first cycle. However, an inactive CuS domain was also identified during the charge-discharge cycles, which is one of the reasons for capacity losses. ${ }^{79}$ The particle sizes of $\mathrm{Li}_{2} \mathrm{~S}$ as well as the favorable contacts among electrode components were revealed to be critical to achieve a high reversible capacity. Unlike $\mathrm{LiCoO}_{2}$ or other intercalation cathodes, $\mathrm{Li}_{2} \mathrm{~S}$ (or $\mathrm{S}$ ) is highly insulating therefore an increased amount of carbon additive is necessary to improve the utilization rate of sulfur. The interface in the sulfur cathode for all-solid-state batteries needs to favor intimate contacts of $\mathrm{Li}_{2} \mathrm{~S}$, carbon and SSE particles. A careful milling process enhances the close contact at the $\mathrm{Li}_{2} \mathrm{~S}$-acetylene black (AB)-SSE "triple junction" before and after cycling (Fig. 8a-d). Therefore, not only a high initial capacity of $\sim 700 \mathrm{~mA} \mathrm{~h} \mathrm{~g}^{-1}$ was achieved from mechanically mixed $\mathrm{Li}_{2} \mathrm{~S} / \mathrm{AB} /$ SSE, the cycling stability and coulombic efficiency are both decent for a solid state battery at room temperature. ${ }^{80}$ Lin et al. fabricated core-shell structured $\mathrm{Li}_{2} \mathrm{~S}$ nanoparticles with $\mathrm{Li}_{2} \mathrm{~S}$ as the core and $\mathrm{Li}_{3} \mathrm{PS}_{4}$ as the shell, functioning as the lithium superionic sulfide (LSS) cathode for lithium-sulfur batteries. $\mathrm{Li}_{3} \mathrm{PS}_{4}$ was found to improve the ionic conductivity of $\mathrm{Li}_{2} \mathrm{~S}$ to $10^{-7} \mathrm{~S} \mathrm{~cm}^{-1}$ at $25{ }^{\circ} \mathrm{C}$, which is 6 orders of magnitude higher than that of bulk $\mathrm{Li}_{2} \mathrm{~S}\left(10^{-13} \mathrm{~S} \mathrm{~cm}^{-1}\right)$. With good contact to the solid electrolyte, the LSS cathode in the all-solid-state Li-S battery shows an initial discharge capacity of $1216 \mathrm{~mA} \mathrm{~h} \mathrm{~g}^{-1}$ (based on the sulfur content) at $60{ }^{\circ} \mathrm{C}$, which accounts for a $73 \%$ utilization of $\mathrm{Li}_{2} \mathrm{~S}$, and still maintains a $70 \%$ capacity after 100 cycles (Fig. 9a). ${ }^{81}$ Reaction of sulfur with $\mathrm{Li}_{3} \mathrm{PS}_{4}$ yields $\mathrm{Li}_{3} \mathrm{PS}_{4+n}$, and sulfur is directly connected to the solid electrolyte. This further helps sulfur to maintain good contact with the solid electrolyte (Fig. 9b). The $\mathrm{Li}_{3} \mathrm{PS}_{4+n}(n=5)$ cathode in an all-solidstate Li-S battery maintains the capacity at $700 \mathrm{~mA} \mathrm{~h} \mathrm{~g}^{-1}$ (based on the sulfur content) after 300 cycles at room temperature and

$\mathrm{S}+2 \mathrm{Li}\left(\mathrm{CH}_{2} \mathrm{CH}_{3}\right)_{3} \mathrm{BH} \rightarrow \mathrm{Li}_{2} \mathrm{~S} \downarrow+2\left(\mathrm{CH}_{2} \mathrm{CH}_{3}\right)_{3} \mathrm{~B}+\mathrm{H}_{2} \uparrow$

(a)

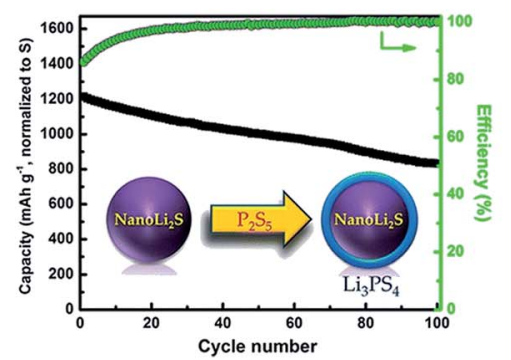

(b)
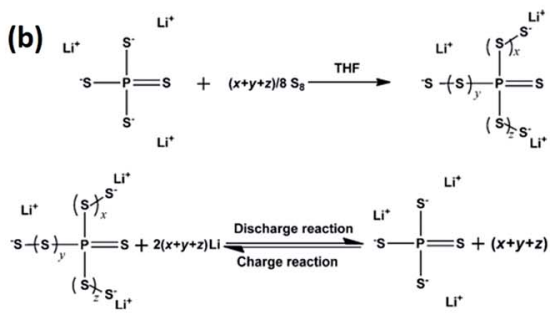

Lr (c)

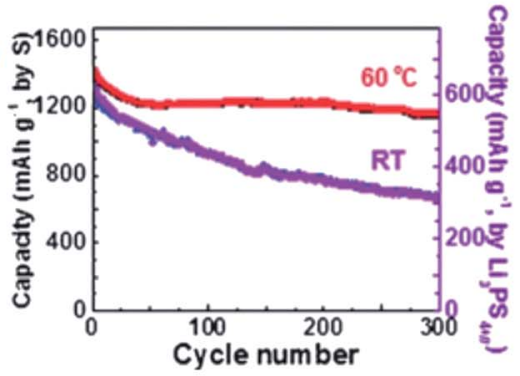

Fig. 9 (a) Cycling performance of LSS as the cathode materials for all-solid-state Li-S batteries at $60{ }^{\circ} \mathrm{C}$ at the rate of $\mathrm{C} / 10$. (b) Preparation of lithium polysulfidophosphates (LPSPS) $\mathrm{Li}_{3} \mathrm{PS}_{4+5}$ and (c) their electrochemical evaluation as the cathode for all-solid-state $\mathrm{Li}-\mathrm{S}$ batteries at the rate of $\mathrm{C} / 10$ at room temperature and $60{ }^{\circ} \mathrm{C}$ (pink/red charge, black/blue discharge). Reprinted from ref. 81 with permission. Copyright 2013 American Chemical Society. Reprinted from ref. 82 with permission. Copyright 2013 John Wiley and Sons. 
even better cycling performance was observed at $60{ }^{\circ} \mathrm{C}$ with a capacity of $1200 \mathrm{~mA} \mathrm{~h} \mathrm{~g}{ }^{-1}$ after 300 cycles. $^{82}$

Unlike intercalation compounds, $\mathrm{S}$ undergoes a conversion reaction which means the volume change is large. Assuming a complete conversion from $\mathrm{S}\left(2.03 \mathrm{~g} \mathrm{~cm}^{-3}\right)$ to $\mathrm{Li}_{2} \mathrm{~S}\left(1.67 \mathrm{~g} \mathrm{~cm}^{-3}\right)$ during the electrochemical processes, the volume expansion is as high as $80 \%{ }^{83}$ How to maintain the original good contact between $\mathrm{S}\left(\mathrm{Li}_{2} \mathrm{~S}\right)$, SSE, and carbon through the entire cycling is quite challenging since the repeated expansion and shrinkage of polysulfide will definitely reduce the intimate contacts among S, SSE, and carbon and form voids, which will quickly increase the interfacial impedances of the cell.

\section{3 $\mathrm{SSE}$ in $\mathrm{Li}-\mathrm{O}_{2}$ batteries}

Different from Li-ion batteries which operate in a closed system, $\mathrm{Li}-\mathrm{O}_{2}$ batteries take advantage of $\mathrm{O}_{2}$ in the environment as the cathode materials. $\mathrm{O}_{2}$ is absorbed into the electrode, usually a carbon substrate, during discharge, gets reduced by accepting electrons, and simultaneously combines with $\mathrm{Li}^{+}$depositing $\mathrm{Li}_{2} \mathrm{O}_{2}$ on the carbon electrode. ${ }^{84}$ Because $\mathrm{Li}_{2} \mathrm{O}_{2}$ is insulating and insoluble in non-aqueous electrolytes, the carbon electrode easily becomes clogged, which terminates the electrochemical reactions especially at high current densities. ${ }^{85}$ On the other hand, if $\mathrm{O}_{2}$ is reduced in an aqueous electrolyte such as $\mathrm{KOH}$, the discharge product is $\mathrm{LiOH}$ which has a high solubility of up to $5 \mathrm{M}^{86}$ However, Li metal is incompatible with water. The combination of $\mathrm{O}_{2}$ reduction in an aqueous electrolyte and use of a metallic $\mathrm{Li}$ anode is realized by using a lithium super-ionic conductor glass film (LISICON, $\mathrm{Li}_{1+x+y} \mathrm{Al}_{x} \mathrm{Ti}_{2-x} \mathrm{Si}_{y} \mathrm{P}_{3-y} \mathrm{O}_{12}$ ) ${ }^{86,87}$ Fig. 10 shows a typical structure of aqueous $\mathrm{Li}-\mathrm{O}_{2}$ batteries in which the LISICON membrane is used to separate reactive lithium metal from the aqueous electrolyte.

Compared with non-aqueous $\mathrm{Li}-\mathrm{O}_{2}$ batteries, both discharge capacity and rate capability of aqueous cells have been improved due to the ease of $\mathrm{LiOH}$ dissolution in the aqueous electrolyte. However, the power of aqueous batteries is largely determined by the LISICON film where Li-ion transport through this membrane is slow. Li-ion transport through the LISICON

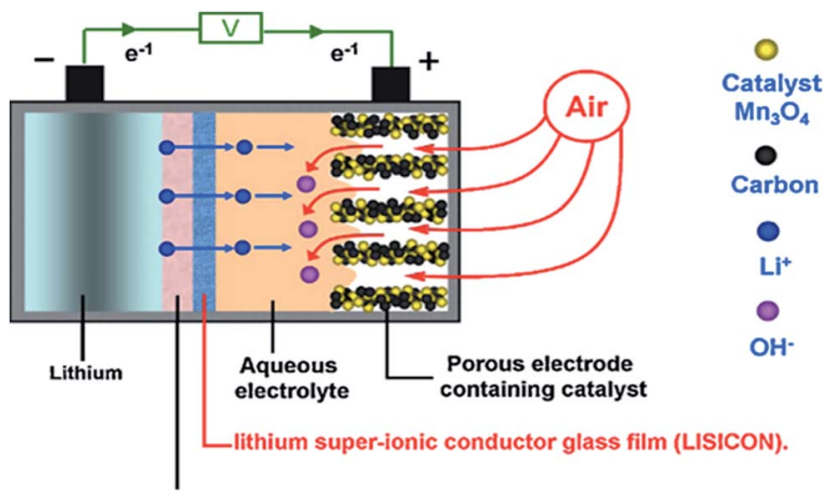

Non-aqueous electrolyte (or organic electrolyte)

Fig. 10 Illustration of a representative structure of an aqueous Li-air battery using LISICON to prevent aqueous solvents from direct contact. The battery shown is in the discharge state. ${ }^{86}$ Reprinted from ref. 86 with permission. Copyright 2010 Elsevier. membrane now becomes the limiting step at high current densities. ${ }^{88}$ Because $\mathrm{Li}_{1+x+y} \mathrm{Al}_{x} \mathrm{Ti}_{2-x} \mathrm{Si}_{y} \mathrm{P}_{3-y} \mathrm{O}_{12}$ (LATP) reacts with lithium metal, a traditional separator such as a Celgard has to be added between $\mathrm{Li}$ and LATP. ${ }^{89}$ The EC-based electrolyte is further adsorbed by the Celgard to wet the surface of both LATP and $\mathrm{Li}$ metal in order to reduce the interfacial resistances. After repeated cycling, the organic electrolytes will be depleted, which is a common phenomenon in rechargeable lithium metal batteries. ${ }^{90}$ From the long-term storage and cycling point of view, LATP is not stable in alkaline solution. ${ }^{91}$ Fig. 11 indicates that LATP glass is easily corroded when immersed in an alkaline electrolyte for only $10 \mathrm{~h}$ (Fig. 11a and b), while it is relatively more stable in a neutral LiCl electrolyte (Fig. 11c). An acidic aqueous electrolyte has less corrosion issue. However, either a neutral or an acidic electrolyte will inevitably change into an alkaline solution during cycling. Therefore, more efforts need to be devoted to increase the stability of LATP in aqueous electrolytes.

\subsection{SSE in Li metal protection}

While the highest impedance exists at the SSE/cathode interface, the interfacial behavior at the SSE/Li interface also critically influences the performance of the whole cell. ${ }^{92}$ Specifically, the interfacial behavior at the SSE/Li interface includes (1) the stability of the SSE against Li metal, (2) SSE/Li interfacial resistance, and (3) the ability of the SSE to prevent Li dendrite growth through the entire solid electrolyte. This interfacial behavior directly dictates the lifespan, energy density, and safety of the all-solid-state batteries.

Garnet/Li interface. Compared with phosphate or sulfidebased SSEs, garnet oxides demonstrate greatly improved stability against lithium metal. ${ }^{15,93,94}$ However, the interfacial resistance at the SSE/Li interface still exists, which affects the power density and long-term stable cycling of the cell. The origin of the interfacial resistance between $\mathrm{Li}$ and the garnet could be from the surface microstructure of LLZO contacting the Li anode, concentration of surface grain boundaries, and impurities in the garnet. Sintering with an appropriate amount of $\mathrm{Al}_{2} \mathrm{O}_{3}$ (ref. 95) or careful engineering of the LLZO surface microstructure ${ }^{96}$ to densify the ceramic electrolyte and close the pores/voids on the LLZO surface effectively reduces the interfacial resistance at the $\mathrm{LLZO} / \mathrm{Li}$ interface. However, during polarization, even for the high density LLZO pellet sintered at high temperatures, a "short circuit" phenomenon in $\mathrm{Li} / \mathrm{LLZO} / \mathrm{Li}$ solid cells was frequently observed once the current density was increased to $0.5 \mathrm{~mA} \mathrm{~cm}^{-2} .^{92}$ Direct observation of a Li dendrite
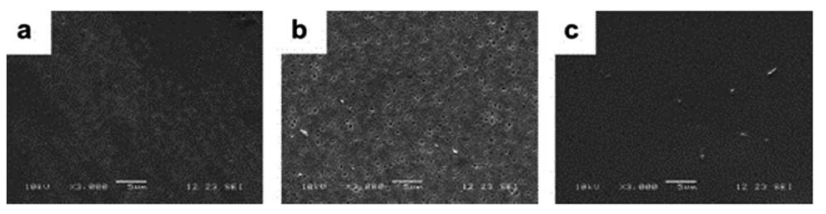

Fig. 11 Scanning electron microscopy images of (a) fresh LATP glass, (b) after storage for $10 \mathrm{~h}$ in $\mathrm{LiOH}$ electrolyte and (c) in $\mathrm{LiCl}$ electrolyte. ${ }^{91}$ Reprinted from ref. 91 with permission. Copyright 2012 Elsevier. 


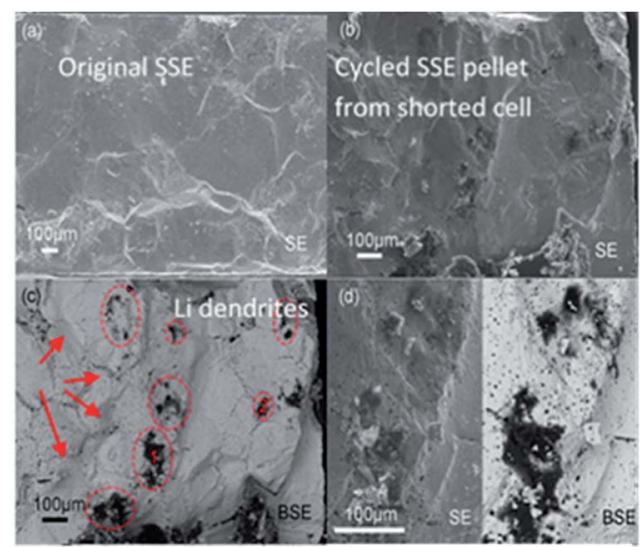

Fig. 12 SEM micrographs of the cross-sectional image of (a) original, (b) shorted Al-containing $\mathrm{Li}_{6.75} \mathrm{La}_{3} \mathrm{Zr}_{1.75} \mathrm{Ta}_{0.25} \mathrm{O}_{12}$ pellet in secondary electron (SE) mode, (c) shorted LLZTO pellet in backscattered electron (BSE) mode to highlight the position of Li dendrites, and (d) enlarged local region images around spot \#1 and \#2 in (c). ${ }^{97}$ Reprinted from ref. 97 with permission. Copyright 2015 Elsevier.

inside a garnet electrolyte has been recently uncovered (Fig. 12), ${ }^{97}$ questioning the effectiveness of solid electrolytes in preventing Li dendrite growth.

In fact, despite the use of polishing and other engineering processes, pores/voids and grain boundaries always exist on the LLZO surface, which provide penetration pathways for $\mathrm{Li}$ dendrites. Even at slightly elevated current densities $(\geq 0.5 \mathrm{~mA}$ $\mathrm{cm}^{-2}$ ), Li dendrites grow quickly along the grain boundaries and interconnected pores in the LLZO pellet and short the cell within a very short period of time during polarization (a few minutes to a few tens of minutes depending on the current density). ${ }^{92}$

Sulfide-electrolyte/Li interface. Benefiting from the high ionic conductivity of sulfide based SSEs, lower impedance with high tolerance on SSE membrane thickness for Li metal protection has been realized. Interestingly, many researchers use other anodes for solid state batteries with sulfide-based SSEs instead of the Li metal batteries, i.e., graphite, ${ }^{98}$ LTO,,${ }^{99}$ or indium. ${ }^{100,101}$ This is probably due to the high reactivity between Li metal and sulfide electrolytes containing high valence elements Ge and P. For crystalline thio-LISICON, $\mathrm{Li}_{10} \mathrm{GeP}_{2} \mathrm{~S}_{12}$, in situ X-ray photoelectron spectroscopy (XPS) has been used to track the interfacial reactions between the SSE and Li metal. It was revealed that the decomposition of $\mathrm{Li}_{10} \mathrm{GeP}_{2} \mathrm{~S}_{12}$ leads to the formation of interphases consisting of $\mathrm{Li}_{3} \mathrm{P}, \mathrm{Li}_{2} \mathrm{~S}$, and a $\mathrm{Li}-\mathrm{Ge}$ alloy, increasing the interfacial resistance (Fig. 13)..$^{102}$ Glass or glass-ceramic sulfide electrolytes, like $x \mathrm{Li}_{2} \mathrm{~S}-(100-x) \mathrm{P}_{2} \mathrm{~S}_{5}$, are fundamentally more stable with Li metal. ${ }^{103}$ If a $80 \mathrm{Li}_{2} \mathrm{~S}-20 \mathrm{P}_{2} \mathrm{~S}_{5}$ membrane is firstly covered by a very thin layer of Li film, followed by attaching standard Li metal electrodes on both sides (Fig. 14a), the interfacial resistance is decreased compared to the direct contact of Li electrodes with the SSE. ${ }^{94}$ The reversibility of lithium dissolution and deposition in rechargeable allsolid-state cells is therefore improved (Fig. 14b and c). Also, a thin film of indium, inserted between a lithium electrode and $80 \mathrm{Li}_{2} \mathrm{~S}-20 \mathrm{P}_{2} \mathrm{~S}_{5} \mathrm{SSE}$ layer, forms a lithium-indium alloy with

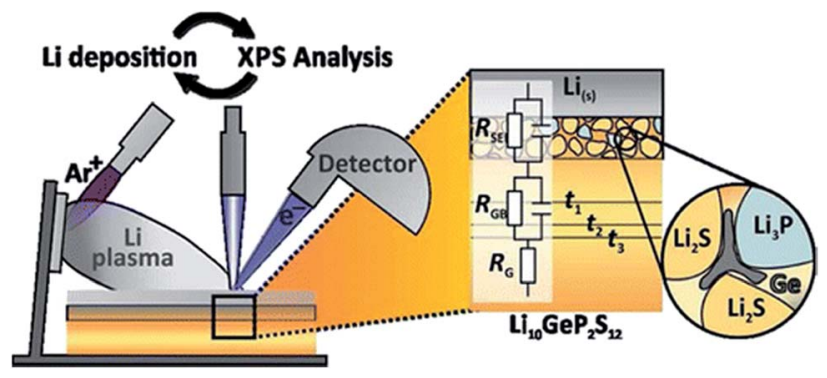

Fig. 13 Schematic of the in situ XPS method to monitor the interactions between $\mathrm{Li}$ and $\mathrm{Li}_{10} \mathrm{GeP}_{2} \mathrm{~S}_{12}$ as well as the interphase formation between them. ${ }^{102}$ Reprinted from ref. 102 with permission. Copyright 2016 American Chemical Society.
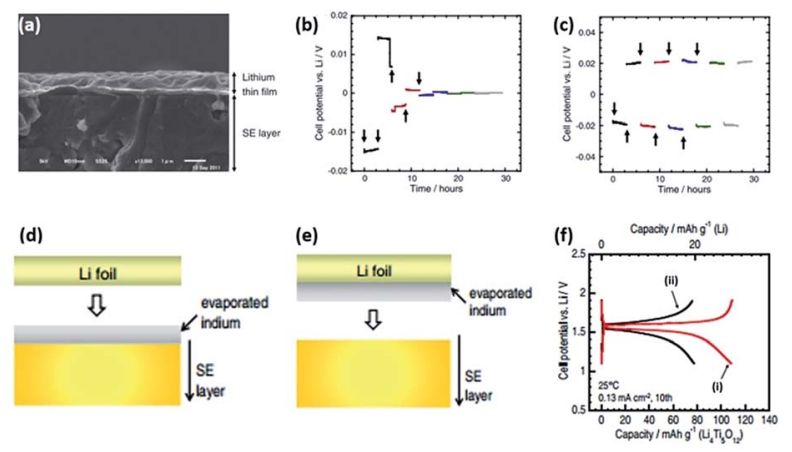

Fig. 14 (a) SEM image of the cross-section of a solid electrolyte (SE) layer with a lithium thin film. Lithium dissolution and deposition curves in the all-solid-state cells. (b) Lithium foil/SE/lithium foil and (c) lithium foil/lithium thin film/SE/lithium thin film/lithium foil at $0.064 \mathrm{~mA}$ $\mathrm{cm}^{-2}$. ${ }^{106}$ Schematics of the interface between lithium and $80 \mathrm{Li}_{2}-$ $\mathrm{S} \cdot 2 \mathrm{P}_{2} \mathrm{~S}_{5}$ SSE are shown in (d) and (e); (d) indium was evaporated on the SSE layer and then lithium foil was attached to the indium thin film and (e) indium was evaporated on lithium foil and the side of indium thin film was attached on the SSE layer. (f) Charge-discharge curves of all-solid-state cells $\mathrm{Li} /$ indium thin film/ $80 \mathrm{Li}_{2} \mathrm{~S} \cdot 2 \mathrm{OP}_{2} \mathrm{~S}_{5} / \mathrm{Li}_{4} \mathrm{Ti}_{5} \mathrm{O}_{12}$, in which indium was evaporated on the SSE layer (i) or on the lithium foil (ii). ${ }^{105}$ Reprinted from ref. 105 with permission. Copyright 2012 Asian Ceramic Society. Reprinted from ref. 106 with permission. Copyright 2016 Elsevier.

a high lithium ion diffusion coefficient ${ }^{104}$ and maintains the intimate interfacial contact during cycling (Fig. 14d and e). Interestingly, if indium is deposited directly on the SSE layer by evaporation, the cell demonstrates better performances than those with indium deposited on Li metal (Fig. 14f). This is because when the In-coated SSE contacts $\mathrm{Li}$, the alloying process occurs between surface In and Li anode which spontaneously "seals" the In/Li interface. Therefore, the resistances existing at the In/SSE and In/Li interfaces are both low. On the other hand, if In is directly coated on the Li metal surface, although In/Li still maintains a very good contact by forming alloys, there is no interaction between the In (coated on the Li surface) and SSE thus the impedance originating from In/SSE is high, leading to inferior electrochemical performances. By incorporating indium thin film, the $\mathrm{Li} / \mathrm{Li}_{4} \mathrm{Ti}_{5} \mathrm{O}_{12}$ cells can be charged and discharged for 120 cycles reversibly and work at a high current density of $1.3 \mathrm{~mA} \mathrm{~cm}{ }^{-2}{ }^{105}$ It is suggested that 
parallel efforts should be pursued to improve the interfacial contact between sulfide-based SSEs and Li metal as well as to address their chemical compatibility issues.

In addition, for a bulk type all-solid-state Li metal battery (1-3 $\mathrm{mA} \mathrm{h} \mathrm{cm}{ }^{-2}$ ), the thickness of the deposited Li metal will range from 10 to $20 \mu \mathrm{m}$. When the battery is discharged, the deposited Li metal will be stripped and break the interface contact between Li metal and the solid electrolyte. Thus, additional pressure is needed to maintain this Li/SSE interface. Obviously, this external pressure source will add on the parasitic weight and decrease the energy density of the system.

\section{Conclusions and perspectives}

ASSLIBs would greatly alleviate the safety concern and simplify the pack management system, for example minimal thermal management is required. After several decades' development of solid electrolytes, lithium ionic conductivity in solid electrolytes has been greatly improved, even exceeding that of liquid electrolytes in a few cases. However, the commercialization of allsolid-state lithium batteries may still have a long way to go due to a few critical issues.

\subsection{Interfacial resistance}

Intimate contact among the active material, carbon additive and solid electrolyte is necessary to facilitate smooth flow channels for both ions and electrons within the whole electrodes. Unlike liquid electrolytes, stiff inorganic solid electrolytes, especially the oxides, show limited deformability. How to create and maintain the intimate interfacial contacts throughout the electrodes before and after repeated cycling has to be addressed. Between the SSE membrane and the cathode, interfacial chemical reactions occur due to the formation of a space charge region, inter-diffusion layers, etc. While buffer layers help to reduce the interfacial impedance, the selection criteria for the buffer layers is still unclear, which calls for more investigation. Similarly, treatment between the SSE and Li anode is also helpful to reduce the interfacial impedance which is more related to improving the "wetting" of $\mathrm{Li}$ on the SSE surface. Depending on the specific applications, different SSEs can be selected, but all of the aforementioned concerns should be considered while designing an ASSLIB.

\subsection{Energy density}

Simply replacing the liquid electrolyte and polyolefin separator by a high density solid electrolyte does not guarantee improvement of the energy density of all-solid-state lithium batteries. A good combination of a high energy cathode, e.g., NCA or S, and a high capacity anode, such as Li metal or Si, is required along with the bipolar cell design. Whether the SSE can effectively prevent Li dendrite growth needs careful investigation with standard and relevant testing protocols.

\subsection{Process \& cost}

For high energy density, the solid electrolyte layer as a separator should be less than 50 microns, and with this thickness, the solid electrolyte layer is very fragile and possesses defects. Therefore, how to efficiently fabricate thin solid electrolyte film with good mechanical strength, no defects, and good contacts with both the cathode and the anode is another big challenge for ASSLIBs. Also, the preparation of solid electrolytes typically necessitates high energy-consuming sintering processes or milling processes, increasing the overall cost for large scale production of solid electrolytes.

The non-deformable nature of inorganic solid electrolytes makes it challenging to achieve good interfacial contacts, defect-free thin film layers and develop a cost-effective process to integrate all solid components into large format cells. The incorporation of soft polymers into stiff solid electrolytes may help overcome these hurdles, ${ }^{107,108}$ which is worthy of more investigation in the future. Testing protocols in the literature need to be consistent with the goal to identify critical fundamental issues and guide researchers to work towards solving the key challenges.

\section{Acknowledgements}

B. Wu, W. Evans and J. Xiao thank Arkansas Research Alliance and Office of Vice Provost for Research and Economic Development at University of Arkansas for the financial support. S. Wang and J. Yang thank the funding from Inamori Foundation and the US Department of Energy under award number DEEE0001384. Z. D. Deng thanks the U.S. Department of Energy Wind and Water Power Technologies Office.

\section{References}

1 P. G. Bruce, Solid state electrochemistry, Cambridge University Press, Cambridge, United Kingdom, 1995.

2 G. C. Farrington and J. L. Briant, Science, 1979, 204, 13711379.

3 A. R. West, Solid State Chemistry and Its Applications, John Wiley and Sons Ltd, New York, 1984.

4 B. B. Owens and G. R. Argue, Science, 1967, 157, 308-310.

5 T. Takahashi, O. Yamamoto, S. Yamada and S. Hayashi, J. Electrochem. Soc., 1979, 126, 1654-1658.

6 M. S. Whittingham, Science, 1976, 192, 1126-1127.

7 U. V. Alpen, A. Rabenau and G. H. Talat, Appl. Phys. Lett., 1977, 30, 621-623.

8 J. B. Goodenough, Solid State Ionics, 1997, 94, 17-25.

9 Z. Liu, W. Fu, E. A. Payzant, X. Yu, Z. Wu, N. J. Dudney, J. Kiggans, K. Hong, A. J. Rondinone and C. Liang, J. Am. Chem. Soc., 2013, 135, 975-978.

10 K. Takada, Acta Mater., 2013, 61, 759-770.

11 J. Sudworth and A. Tiley, Sodium Sulphur Battery, Chapman \& Hall, London, England, 1985.

12 B. Dunn, B. Schwarz, J. Thomas and P. Morgan, Solid State Ionics, 1988, 28, 301-305.

13 N. Baffier, J. Badot and P. Colomban, Mater. Res. Bull., 1981, 16, 259-265.

14 Q. Wang, P. Ping, X. Zhao, G. Chu, J. Sun and C. Chen, J. Power Sources, 2012, 208, 210-224. 
15 N. Kamaya, K. Homma, Y. Yamakawa, M. Hirayama, R. Kanno, M. Yonemura, T. Kamiyama, Y. Kato, S. Hama and K. Kawamoto, Nat. Mater., 2011, 10, 682-686.

16 Y. Kato, S. Hori, T. Saito, K. Suzuki, M. Hirayama, A. Mitsui, M. Yonemura, H. Iba and R. Kanno, Nat. Energy, 2016, 1, 16030.

17 Y.-S. Hu, Nat. Energy, 2016, 1, 16042.

18 A. C. Luntz, J. Voss and K. Reuter, J. Phys. Chem. Lett., 2015, 6, 4599-4604.

19 T. Minami, A. Hayashi and M. Tatsumisago, Solid State Ionics, 2006, 177, 2715-2720.

20 V. Thangadurai, S. Adams and W. Weppner, Chem. Mater., 2004, 16, 2998-3006.

21 E. J. Cussen, J. Mater. Chem., 2010, 20, 5167-5173.

22 R. Jalem, M. Rushton, W. Manalastas Jr, M. Nakayama, T. Kasuga, J. A. Kilner and R. W. Grimes, Chem. Mater., 2015, 27, 2821-2831.

23 E. Masdupuy, Ann. Chim., 1957, 13, 527.

24 P. N. Iyer and A. J. Smith, Acta Crystallogr., 1967, 23, 470.

25 L. Latie, G. Villeneuve, D. Conte and G. Le Flem, J. Solid State Chem., 1984, 51, 293-299.

26 Y. Inaguma, C. Liquan, M. Itoh, T. Nakamura, T. Uchida, H. Ikuta and M. Wakihara, Solid State Commun., 1993, 86, 689-693.

27 H. M. Kasper, Inorg. Chem., 1969, 8, 1000-1002.

28 R. Murugan, V. Thangadurai and W. Weppner, Angew. Chem., Int. Ed., 2007, 46, 7778-7781.

29 C. Deviannapoorani, L. Dhivya, S. Ramakumar and R. Murugan, J. Power Sources, 2013, 240, 18-25.

30 J. B. Goodenough, H. Y. P. Hong and J. A. Kafalas, Mater. Res. Bull., 1976, 11, 203-220.

31 M. A. Subramanian, R. Subramanian and A. Clearfield, Solid State Ionics, 1986, 18-19, 562-569.

32 H. Aono, E. Sugimoto, Y. Sadaoka, N. Imanaka and G. Y. Adachi, J. Electrochem. Soc., 1990, 137, 1023-1027.

33 J. Fu, Solid State Ionics, 1997, 96, 195-200.

34 X. Xu, Z. Wen, X. Yang and L. Chen, Mater. Res. Bull., 2008, 43, 2334-2341.

35 J. B. Bates, N. J. Dudney, G. R. Gruzalski, R. A. Zuhr, A. Choudhury, C. F. Luck and J. D. Robertson, Solid State Ionics, 1992, 53-56, 647-654.

36 R. Mercier, J. P. Malugani, B. Fahys and G. Robert, Solid State Ionics, 1981, 5, 663-666.

37 R. Kanno, T. Hata, Y. Kawamoto and M. Irie, Solid State Ionics, 2000, 130, 97-104.

38 N. Kamaya, K. Homma, Y. Yamakawa, M. Hirayama, R. Kanno, M. Yonemura, T. Kamiyama, Y. Kato, S. Hama, K. Kawamoto and A. Mitsui, Nat. Mater., 2011, 10, 682-686.

39 O. Kwon, M. Hirayama, K. Suzuki, Y. Kato, T. Saito, M. Yonemura, T. Kamiyama and R. Kanno, J. Mater. Chem. A, 2015, 3, 438-446.

40 Y. Seino, T. Ota, K. Takada, A. Hayashi and M. Tatsumisago, Energy Environ. Sci., 2014, 7, 627-631.

41 B. D. McCloskey, J. Phys. Chem. Lett., 2015, 6, 4581-4588.

42 K. Abraham, J. Phys. Chem. Lett., 2015, 6, 830-844.

43 Y. S. Jung, D. Y. Oh, Y. J. Nam and K. H. Park, Isr. J. Chem., 2015, 55, 472-485.
44 A. Sakuda, A. Hayashi and M. Tatsumisago, Sci. Rep., 2013, 3, 2261, DOI: 10.1038/srep02261.

45 N. J. Dudney, W. C. West and J. Nanda, Handbook of Solid State Batteries, World Scientific Series in Materials and Energy, ISSN: 2335-6596, 2nd edn, 2016.

46 B. D. McCloskey, J. Phys. Chem. Lett., 2015, 6, 4581-4588.

47 J. Haruyama, K. Sodeyama, L. Han, K. Takada and Y. Tateyama, Chem. Mater., 2014, 26, 4248-4255.

48 C. Ma, K. Chen, C. Liang, C.-W. Nan, R. Ishikawa, K. More and M. Chi, Energy Environ. Sci., 2014, 7, 1638-1642.

49 K. Takada, N. Ohta, L. Zhang, K. Fukuda, I. Sakaguchi, R. Ma, M. Osada and T. Sasaki, Solid State Ionics, 2008, 179, 1333-1337.

50 A. Sakuda, A. Hayashi and M. Tatsumisago, Chem. Mater., 2010, 22, 949-956.

51 T. Okumura, T. Nakatsutsumi, T. Ina, Y. Orikasa, H. Arai, T. Fukutsuka, Y. Iriyama, T. Uruga, H. Tanida and Y. Uchimoto, J. Mater. Chem., 2011, 21, 10051-10060.

52 N. Nitta, F. Wu, J. T. Lee and G. Yushin, Mater. Today, 2015, 18, 252-264.

53 C. Liu, Z. G. Neale and G. Cao, Mater. Today, 2016, 19, 109123.

54 K. Ishidzu, Y. Oka and T. Nakamura, Solid State Ionics, 2016, 288, 176-179.

55 F. Du, N. Zhao, Y. Li, C. Chen, Z. Liu and X. Guo, J. Power Sources, 2015, 300, 24-28.

56 N. Ohta, K. Takada, L. Zhang, R. Ma, M. Osada and T. Sasaki, Adv. Mater., 2006, 18, 2226-2229.

57 N. Ohta, K. Takada, I. Sakaguchi, L. Zhang, R. Ma, K. Fukuda, M. Osada and T. Sasaki, Electrochem. Commun., 2007, 9, 1486-1490.

58 A. Sakuda, H. Kitaura, A. Hayashi, K. Tadanaga and M. Tatsumisago, J. Electrochem. Soc., 2009, 156, A27-A32.

59 K. Takada, Langmuir, 2013, 29, 7538-7541.

60 K. Takada, N. Ohta, L. Zhang, X. Xu, B. T. Hang, T. Ohnishi, M. Osada and T. Sasaki, Solid State Ionics, 2012, 225, 594597.

61 K. Leung and A. Leenheer, J. Phys. Chem. C, 2015, 119, 10234-10246.

62 T. Ohtomo, A. Hayashi, M. Tatsumisago, Y. Tsuchida, S. Hama and K. Kawamoto, J. Power Sources, 2013, 233, 231-235.

63 K. H. Kim, Y. Iriyama, K. Yamamoto, S. Kumazaki, T. Asaka, K. Tanabe, C. A. Fisher, T. Hirayama, R. Murugan and Z. Ogumi, J. Power Sources, 2011, 196, 764-767.

64 S. Ohta, T. Kobayashi, J. Seki and T. Asaoka, J. Power Sources, 2012, 202, 332-335.

65 F. Mizuno, C. Yada and H. Iba, in Lithium-Ion Batteries: Advances and Applications, Elsevier, Amsterdam, 2014, pp. 273-291.

66 L. Cheng, E. J. Crumlin, W. Chen, R. Qiao, H. Hou, S. F. Lux, V. Zorba, R. Russo, R. Kostecki and Z. Liu, Phys. Chem. Chem. Phys., 2014, 16, 18294-18300.

67 M. Sumita, Y. Tanaka, M. Ikeda and T. Ohno, J. Phys. Chem. C, 2016, 120, 13332-13339.

68 F. Han, Y. Zhu, X. He, Y. Mo and C. Wang, Adv. Energy Mater., 2016, 6, 1501590, DOI: 10.1002/aenm.201501590. 
69 Y. Zhu, X. He and Y. Mo, J. Mater. Chem. A, 2016, 4, 32533266.

70 N. D. Lepley and N. A. W. Holzwarth, Phys. Rev. B: Condens. Matter Mater. Phys., 2015, 92, 214201.

71 Y. Zhu, X. He and Y. Mo, ACS Appl. Mater. Interfaces, 2015, 7, 23685-23693.

72 J. Xiao, Adv. Energy Mater., 2015, 5, 1501102.

73 P. G. Bruce, S. A. Freunberger, L. J. Hardwick and J.-M. Tarascon, Nat. Mater., 2012, 11, 19-29.

74 D. Aurbach, E. Pollak, R. Elazari, G. Salitra, C. S. Kelley and J. Affinito, J. Electrochem. Soc., 2009, 156, A694-A702.

75 X. Ji and L. F. Nazar, J. Mater. Chem., 2010, 20, 9821-9826.

76 A. Hayashi, T. Ohtomo, F. Mizuno, K. Tadanaga and M. Tatsumisago, Electrochem. Commun., 2003, 5, 701-705.

77 T. Kobayashi, Y. Imade, D. Shishihara, K. Homma, M. Nagao, R. Watanabe, T. Yokoi, A. Yamada, R. Kanno and T. Tatsumi, J. Power Sources, 2008, 182, 621-625.

78 T. Yamada, S. Ito, R. Omoda, T. Watanabe, Y. Aihara, M. Agostini, U. Ulissi, J. Hassoun and B. Scrosati, J. Electrochem. Soc., 2015, 162, A646-A651.

79 A. Hayashi, R. Ohtsubo, T. Ohtomo, F. Mizuno and M. Tatsumisago, J. Power Sources, 2008, 183, 422-426.

80 M. Nagao, A. Hayashi and M. Tatsumisago, J. Mater. Chem., 2012, 22, 10015-10020.

81 Z. Lin, Z. Liu, N. J. Dudney and C. Liang, ACS Nano, 2013, 7, 2829-2833.

82 Z. Lin, Z. Liu, W. Fu, N. J. Dudney and C. Liang, Angew. Chem., 2013, 125, 7608-7611.

83 D.-W. Wang, Q. Zeng, G. Zhou, L. Yin, F. Li, H.-M. Cheng, I. R. Gentle and G. Q. M. Lu, J. Mater. Chem. A, 2013, 1, 9382-9394.

84 K. Abraham and Z. Jiang, J. Electrochem. Soc., 1996, 143, 1-5. 85 J. Xiao, D. Wang, W. Xu, D. Wang, R. E. Williford, J. Liu and J.-G. Zhang, J. Electrochem. Soc., 2010, 157, A487-A492.

86 Y. Wang and H. Zhou, J. Power Sources, 2010, 195, 358-361.

87 S. J. Visco, B. D. Katz, Y. S. Nimon and L. C. De Jonghe, US Pat., 7282295, 2007.

88 P. He, Y. Wang and H. Zhou, Electrochem. Commun., 2010, 12, 1686-1689.

89 T. Zhang, N. Imanishi, S. Hasegawa, A. Hirano, J. Xie, Y. Takeda, O. Yamamoto and N. Sammes, J. Electrochem. Soc., 2008, 155, A965-A969.
90 C. M. López, J. T. Vaughey and D. W. Dees, J. Electrochem. Soc., 2009, 156, A726-A729.

91 F. Ding, W. Xu, Y. Shao, X. Chen, Z. Wang, F. Gao, X. Liu and J.-G. Zhang, J. Power Sources, 2012, 214, 292-297.

92 R. Sudo, Y. Nakata, K. Ishiguro, M. Matsui, A. Hirano, Y. Takeda, O. Yamamoto and N. Imanishi, Solid State Ionics, 2014, 262, 151-154.

93 P. Knauth, Solid State Ionics, 2009, 180, 911-916.

94 K. Ishiguro, Y. Nakata, M. Matsui, I. Uechi, Y. Takeda, O. Yamamoto and N. Imanishi, J. Electrochem. Soc., 2013, 160, A1690-A1693.

95 H. Buschmann, S. Berendts, B. Mogwitz and J. Janek, J. Power Sources, 2012, 206, 236-244.

96 L. Cheng, W. Chen, M. Kunz, K. Persson, N. Tamura, G. Chen and M. Doeff, ACS Appl. Mater. Interfaces, 2015, 7, 2073-2081.

97 Y. Ren, Y. Shen, Y. Lin and C.-W. Nan, Electrochem. Commun., 2015, 57, 27-30.

98 S. Ito, S. Fujiki, T. Yamada, Y. Aihara, Y. Park, T. Y. Kim, S.-W. Baek, J.-M. Lee, S. Doo and N. Machida, J. Power Sources, 2014, 248, 943-950.

99 Y. Seino, T. Ota and K. Takada, J. Power Sources, 2011, 196, 6488-6492.

100 M. Tatsumisago, F. Mizuno and A. Hayashi, J. Power Sources, 2006, 159, 193-199.

101 K. Takada, N. Aotani, K. Iwamoto and S. Kondo, Solid State Ionics, 1996, 86, 877-882.

102 S. Wenzel, S. Randau, T. Leichtweiß, D. A. Weber, J. Sann, W. G. Zeier and J. Janek, Chem. Mater., 2016, 28, 2400-2407.

103 A. Hayashi, S. Hama, F. Mizuno, K. Tadanaga, T. Minami and M. Tatsumisago, Solid State Ionics, 2004, 175, 683-686.

104 C. J. Wen and R. A. Huggins, Mater. Res. Bull., 1980, 15, 1225-1234.

105 M. Nagao, A. Hayashi and M. Tatsumisago, Electrochemistry, 2012, 80, 734-736.

106 M. Nagao, A. Hayashi and M. Tatsumisago, Electrochem. Commun., 2012, 22, 177-180.

107 I. Villaluenga, K. H. Wujcik, W. Tong, D. Devaux, D. H. C. Wong, J. M. DeSimone and N. P. Balsara, PNAS, 2015, 113, 52-57.

108 J.-H. Choi, C.-H. Lee, J.-H. Yu, C.-H. Doh and S.-M. Lee, J. Power Sources, 2015, 274, 458-463. 